\title{
Decoupling Control for Dual-Winding Bearingless Switched Reluctance Motor Based on Improved Inverse System Method
}

\author{
Zhiying Zhu, ${ }^{1}$ Yukun Sun, ${ }^{1}$ and Ye Yuan ${ }^{2}$ \\ ${ }^{1}$ School of Electric Power Engineering, Nanjing Institute of Technology, Nanjing 211167, China \\ ${ }^{2}$ School of Electrical and Information Engineering, Jiangsu University, Zhenjiang 212013, China \\ Correspondence should be addressed to Zhiying Zhu; zyzhu@njit.edu.cn
}

Received 12 October 2016; Revised 4 January 2017; Accepted 11 January 2017; Published 16 February 2017

Academic Editor: Luis J. Yebra

Copyright (c) 2017 Zhiying Zhu et al. This is an open access article distributed under the Creative Commons Attribution License, which permits unrestricted use, distribution, and reproduction in any medium, provided the original work is properly cited.

\begin{abstract}
Dual-winding bearingless switched reluctance motor (BSRM) is a multivariable high-nonlinear system characterized by strong coupling, and it is not completely reversible. In this paper, a new decoupling control strategy based on improved inverse system method is proposed. Robust servo regulator is adopted for the decoupled plants to guarantee control performances and robustness. A phase dynamic compensation filter is also designed to improve system stability at high-speed. In order to explain the advantages of the proposed method, traditional methods are compared. The tracking and decoupling characteristics as well as disturbance rejection and robustness are deeply analyzed. Simulation and experiments results show that the decoupling control of dual-winding BSRM in both reversible and irreversible domains can be successfully resolved with the improved inverse system method. The stability and robustness problems induced by inverse controller can be effectively solved by introducing robust servo regulator and dynamic compensation filter.
\end{abstract}

\section{Introduction}

Switched reluctance motors (SRM) are favored in harsh conditions and some high-speed driving applications owing to their rugged structure, fault tolerance, and robustness [1-4]. The drawback is that SRM running at high-speed usually suffer from the mechanical friction between shaft and bearing. Magnetic bearings (MB) present the advantages of no lubrication and wear during high-speed operation, but $\mathrm{MB}$ need extra axial space; thus, the shaft length of magnetic-bearing SRM is usually increased, and its critical rotating speed is limited. Bearingless switched reluctance motor (BSRM) that combines MB with SRM is becoming a promising alternative to the traditional SRM because of its inherent superior features, such as zero friction, no lubrication, no wear, short rotor shaft, high critical speed, long life, and adjustable bearing stiffness and damping [5].

Recently, several types of BSRM have been proposed, for example, dual-winding [6], single-winding [7, 8], hybridrotor [9], hybrid-stator [10], double-stator [11], and permanent magnet-biased [12,13] types. Among these types, dual-winding BSRM possesses double saliency with two kinds of concentrated stator windings. Dual-winding BSRM offers simpler structure and clearer winding function and thus receives more attention than other types of BSRM. Conversely, the double saliency leads to complex nonlinear characteristics, and dual-winding results in mutual coupling between the torque and radial force. Therefore, dual-winding BSRM is a multivariable, high-nonlinear motor characterized by strong coupling, which presents a challenging control problem.

Regarding the control of dual-winding BSRM, the typical method is square-wave current control proposed by Takemoto et al. In $[14,15]$, the square-wave current control has realized the stable operation of dual-winding BSRM from no load to full load, and the influences of magnetic saturation and coupling effects on the torque and radial force are considered [16, 17]. Furthermore, an independent control strategy of average torque and radial force was presented [18]. In this method, the current calculating algorithm is deduced to minimize the magnitude of instantaneous torque in the levitation region. In addition, the least magnetomotive force strategy was investigated to enhance the availability of winding currents and to decrease the 
torque ripple and stator vibration [19]. Recently, interest in the study on decoupling control has been increasing [2024], mainly including the differential geometric method [20, 21] and inverse system method [22-25]. Compared with the former, the latter needs neither to use the complex nonlinear coordinate transformation nor to transfer the nonlinear control problems into geometric ones. Therefore, the inverse system method is relatively simple to implement in practice. In detail, the inverse system method includes analytic inverse system [22, 23] and intelligent ones [24, 25]. Compared with analytic inverse system, intelligent ones need not rely on the precise mathematical model, but they usually require large allocations of computer resources that are often typically restricted in high-speed system. Hence, analytic inverse system method has attracted more attention than intelligent ones in high-speed magnetically suspended field [26, 27].

The implementation of analytic inverse system method requires the controlled object to be reversible. However, it is difficult to satisfy the reversibility in practical system. According to [23], the dual-winding BSRM is not completely reversible and its working area includes two parts: reversible and irreversible domains. Traditional analytic inverse system method can only realize the decoupling control in the reversible domain, while the decoupling control in the irreversible domain cannot be realized. To solve these issues, a modified inverse decoupling control method for BSRM operating in irreversible domain is proposed by authors in [23]. However, it is known that the analytic inverse controller usually affects the robustness and stability of system because uncertainties and model errors always exist in reality. Especially at high-speed, the mathematical model is not equivalent to the actual system because the former does not consider the amplifiers bandwidth and computation delay, and these dynamics can degrade decoupling performance and even endanger system stability. To combat these adverse effects, proportion-integrationdifferentiation (PID) control [22-25] and internal model control [26] have been typically employed for the decoupled plants. Nevertheless, nearly all these methods experience difficulty in realizing tracking and robustness independently [27].

This study presents a novel decoupling control strategy based on improved inverse system method to realize the decoupling control of dual-winding BSRM in both the reversible and irreversible domains. Robust servo regulator is adopted for the decoupled plants to guarantee control performances and robustness. A phase dynamic compensation filter (DCF) is also designed to improve system stability at high-speed. One main contribution of this study is to demonstrate that the decoupling control of dual-winding BSRM at high-speed (up to 20,000 r/min) in both reversible and irreversible domains can all be successfully resolved with the improved inverse system method. The other contribution is to show that the stability and robustness problems induced by inverse controller can be effectively solved by introducing robust servo regulator and DCF.

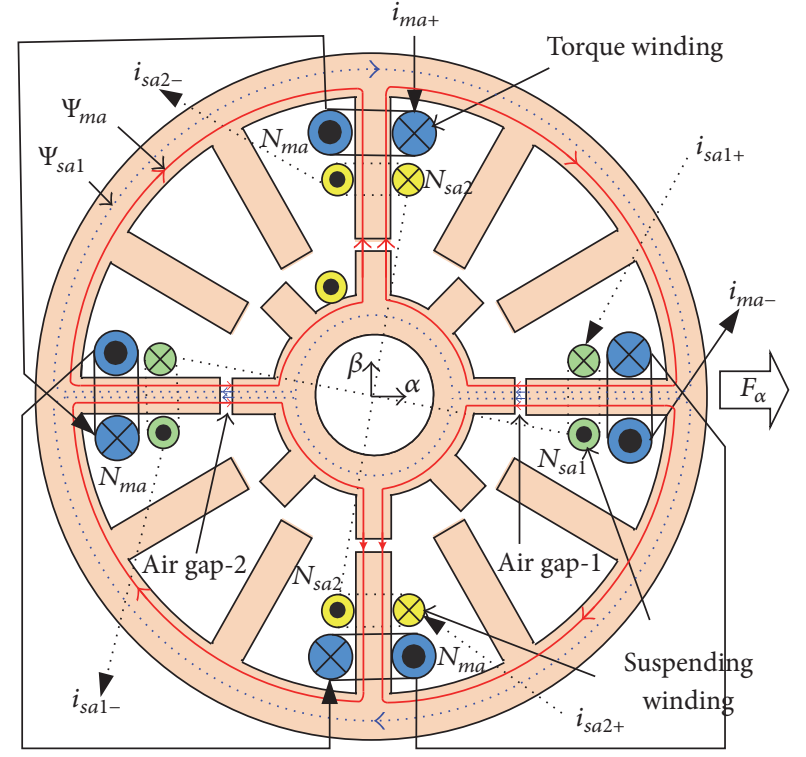

FIGURE 1: Principle of radial force production of dual-winding BSRM.

\section{Principle and Characteristic Analysis of the Dual-Winding BSRM}

2.1. Radial Force Production Principle of Dual-Winding BSRM. Figure 1 shows the principle of radial force production of dual-winding BSRM with A-phase windings. The torque winding $N_{m a}$ consists of four coils connected in series, and the suspending windings $N_{s a 1}$ and $N_{s a 2}$ consist of two coils each. When the torque winding $N_{m a}$ and suspending winding $N_{s a 1}$ conduct the currents $i_{m a}$ and $i_{s a 1}$, respectively, the symmetrical four-pole main fluxes $\Psi_{m a}$ and two-pole suspending fluxes $\Psi_{s a 1}$ should be produced. The flux density in air gap-1 increases but decreases in air gap-2. Therefore, this superimposed magnetic field results in the radial force $F_{\alpha}$ acting on the rotor in the $\alpha$-axis. The radial force $F_{\beta}$ in the $\beta$-axis can also be produced in the same manner. Radial force in any desired direction can be produced by generating the two radial forces. This principle can be similarly applied to the B-phase and C-phase windings.

2.2. Mathematical Model of Dual-Winding BSRM. Neglecting the leakage flux and saturation effects, the theoretical formulae of the torque and radial forces can be derived from the derivatives of the stored magnetic energy $W$ with respect to displacements $\alpha$ and $\beta$ and rotor position $\theta$ as [17].

$$
\begin{aligned}
& F_{\alpha}=\frac{\partial W}{\partial \alpha}=i_{m a}\left(K_{f 1} \cdot i_{s a 1}-K_{f 2} \cdot i_{s a 2}\right), \\
& F_{\beta}=\frac{\partial W}{\partial \beta}=i_{m a}\left(K_{f 2} \cdot i_{s a 1}+K_{f 1} \cdot i_{s a 2}\right), \\
& T_{e}=\frac{\partial W}{\partial \theta}=K_{t}\left(2 N_{m}^{2} i_{m a}^{2}+N_{s}^{2} i_{s a 1}^{2}+N_{s}^{2} i_{s a 2}^{2}\right),
\end{aligned}
$$

where $N_{m}$ and $N_{s}$ are the number of turns of torque winding and suspending windings; $i_{m a}, i_{s a 1}$, and $i_{s a 2}$ are the 
currents in A-phase torque winding and suspending winding, respectively; $F_{\alpha}$ and $F_{\beta}$ are the radial force acting on rotor in $\alpha$ - and $\beta$-axis; $T_{e}$ is the electromagnetic torque acting on rotor; and $K_{f 1}, K_{f 2}$, and $K_{t}$ are the proportional coefficients of radial force and torque, and they are the functions of the rotor position and motor dimensions [17].

$$
\begin{aligned}
K_{f 1} & =N_{m} N_{s}\left(\frac{\mu_{0} l r(\pi-12|\theta|)}{6 \delta^{2}}\right. \\
& \left.+\frac{32 \mu_{0} l r c|\theta|}{\pi\left(4 r c|\theta| \delta+\pi \delta^{2}\right)}\right), \\
K_{f 2} & =N_{m} N_{s}\left(\frac{\mu_{0} l r(\pi-12|\theta|)|\theta|}{12 \delta^{2}}-\frac{2 \mu_{0} l}{\delta}\right. \\
& \left.+\frac{16 \mu_{0} l c\left(r|\theta|^{2}+2 \delta\right)}{\pi\left(4 r c|\theta| \delta+\pi \delta^{2}\right)}\right), \\
K_{t}= & \begin{cases}\frac{\mu_{0} l r}{\delta}-\frac{16 \mu_{0} l r(\delta-r|\theta|)}{(4 \delta-\pi r|\theta|)^{2}} & -\frac{\pi}{12} \leq \theta \leq 0 \\
-\frac{\mu_{0} l r}{\delta}+\frac{16 \mu_{0} l r(\delta-r|\theta|)}{(4 \delta-\pi r|\theta|)^{2}} & 0 \leq \theta \leq \frac{\pi}{12},\end{cases}
\end{aligned}
$$

where $\delta$ is the air-gap length, $r$ is the radius of the rotor pole, $l$ is the axial stack length, $\theta$ is the rotor position from the aligned position of exciting phase, $\mu_{0}$ is the permeability of vacuum $\left(4 \pi \times 10^{-7}\right)$, and $c$ is a constant of 1.49 .

The actual control performance of the inverse system method largely depends on the precision of the mathematical model. The major factors that affect the accuracy of the model are the torque and radial forces. Fortunately, the theoretical relationships (1) are verified with experimental results in [17] by considering cross coupling and fringing fluxes. The test values show good agreements with those from the model, confirming that formulae (1) are reasonable. Mathematical model (1) is used in this study for its convenience and accuracy.

According to Newton's second law and rotor dynamics, the dynamic model of the rotor can be described as

$$
\begin{aligned}
& m \ddot{\alpha}=F_{\alpha}, \\
& m \ddot{\beta}=F_{\beta}-m g, \\
& J \dot{\omega}=T_{e}-T_{L},
\end{aligned}
$$

where $m$ is the mass of the rotor, $g$ is the acceleration of gravity, $J$ is the moments of inertia of the rotor, $\alpha$ and $\beta$ are the linear displacements of the rotor in $\alpha$ - and $\beta$-axis, respectively, $\omega$ is the mechanical angular velocity of the rotor, and $T_{L}$ refers to the load torque. Substituting (1) into (3) yields

$$
\begin{aligned}
& \ddot{\alpha}=\frac{1}{m}\left[i_{m a}\left(K_{f 1} \cdot i_{s a 1}-K_{f 2} \cdot i_{s a 2}\right)\right], \\
& \ddot{\beta}=\frac{1}{m}\left[i_{m a}\left(K_{f 2} \cdot i_{s a 1}+K_{f 1} \cdot i_{s a 2}\right)\right]-g, \\
& \dot{\omega}=\frac{1}{J}\left[K_{t}\left(2 N_{m}^{2} i_{m a}^{2}+N_{s}^{2} i_{s a 1}^{2}+N_{s}^{2} i_{s a 2}^{2}\right)-T_{L}\right] .
\end{aligned}
$$

2.3. Nonlinearity and Coupling Characteristics of DualWinding BSRM. According to the first equation of the equations set in (1), $F_{\alpha}$ is the function of $i_{s a 1}, i_{s a 2}$, and $i_{m a}$. Therefore, $F_{\alpha}$ is coupling with $F_{\beta}$ and $T_{e}$. The coupling of $F_{\beta}$ and $T_{e}$ can be drawn similarly. Dynamic coupling always exists among $F_{\alpha}, F_{\beta}$, and $T_{e}$. Also from equations set in (1), $T_{e}$ is quadratic to $i_{m a}, i_{s a 1}$, and $i_{s a 2}$, and $F_{\alpha}$ and $F_{\beta}$ are proportional to the product of $i_{m a}, i_{s a 1}$, and $i_{s a 2}$. Strong nonlinearity exists between $\mathbf{F}=\left\{F_{\alpha}, F_{\beta}, T_{e}\right\}$ and $\mathbf{i}=$ $\left\{i_{m a}, i_{s a 1}, i_{s a 2}\right\}$, and the greater the current value, the stronger the nonlinearity.

The coupling and nonlinearity characteristics can be seen clearly with finite element analysis (FEA). Figure 2 shows the FEA results of $T_{e}, F_{\beta}$, and $F_{\alpha}$ at different $\theta$ with different $i_{s a 2}$ under the conditions $\alpha=\beta=0 \mathrm{~mm}, i_{m a}=10 \mathrm{~A}$, and $i_{s a 2}=$ $0 \mathrm{~A}$.

As shown in Figure 2(a), torque $T_{e}$ is nonlinear to rotor position $\theta$, and the greater the current $i_{s a 2}$, the greater the torque $T_{e}$. Thus, current $i_{s a 2}$ can produce torque $T_{e}$; that is, torque $T_{e}$ is coupling with radial force $F_{\beta}$. Figure 2(b) illustrates that radial force $F_{\beta}$ is nonlinear to rotor position $\theta$ and current $i_{\text {sa2 }}$. Figure 2(c) demonstrates that radial force $F_{\alpha}$ continues to exist when current $i_{s a 1}=0$, and the greater the current $i_{s a 2}$, the greater the radial force $F_{\alpha}$. At the same current $i_{s a 2}$, radial force $F_{\alpha}$ is greatest at $\theta=-15^{\circ}$.

According to the aforementioned analysis, we conclude that the dual-winding BSRM is a multivariable highnonlinear motor with strong coupling, not only between the radial forces but also between the torque and radial forces. To realize the rotor translation and motion control, the decoupling control between the torque and radial forces should be achieved.

\section{Decoupling Control of Dual-Winding BSRM}

3.1. Reversibility of Dual-Winding BSRM. According to (4), state variables $\mathbf{x}$, input variables $\mathbf{u}$, and output variables $\mathbf{y}$ can be defined as follows:

$$
\begin{aligned}
& \mathbf{x}=\left[x_{1}, x_{2}, x_{3}, x_{4}, x_{5}, x_{6}\right]^{\mathrm{T}}=[\alpha, \beta, \theta, \dot{\alpha}, \dot{\beta}, \omega]^{\mathrm{T}}, \\
& \mathbf{u}=\left[u_{1}, u_{2}, u_{3}\right]^{\mathrm{T}}=\left[i_{s a 1}, i_{s a 2}, i_{m a}\right]^{\mathrm{T}}, \\
& \mathbf{y}=\left[y_{1}, y_{2}, y_{3}\right]^{\mathrm{T}}=[\alpha, \beta, \omega]^{\mathrm{T}} .
\end{aligned}
$$

Then, the corresponding state-variable equation of the nonlinear system (4) can be rewritten as

$$
\begin{aligned}
\dot{\mathbf{x}} & =f(\mathbf{x}, \mathbf{u}) \\
& =\left[\begin{array}{c}
x_{4} \\
x_{5} \\
x_{6} \\
\frac{1}{m}\left[u_{3}\left(K_{f 1} \cdot u_{1}-K_{f 2} \cdot u_{2}\right)\right] \\
\frac{1}{m}\left[u_{3}\left(K_{f 2} \cdot u_{1}-K_{f 1} \cdot u_{2}\right)\right]-g \\
\frac{1}{J}\left[K_{t}\left(2 N_{m}^{2} u_{3}^{2}+N_{s}^{2} u_{1}^{2}+N_{s}^{2} u_{2}^{2}\right)-T_{L}\right]
\end{array}\right] .
\end{aligned}
$$




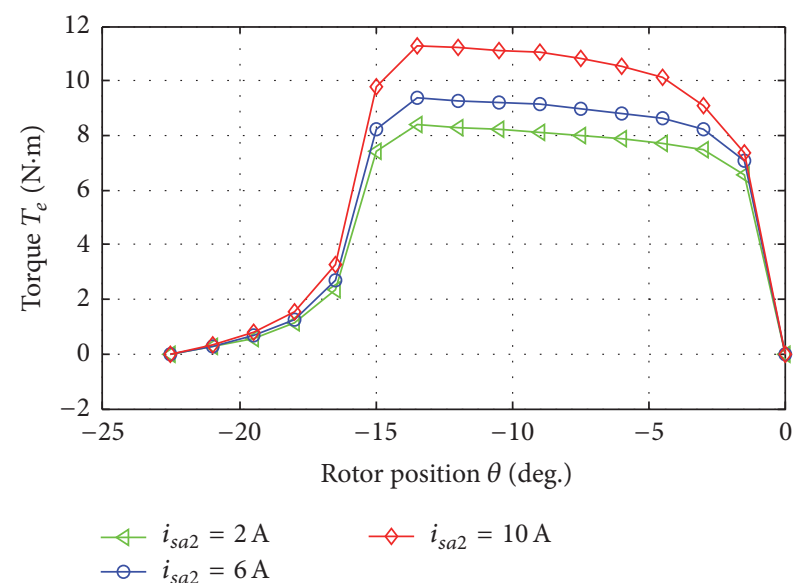

(a)

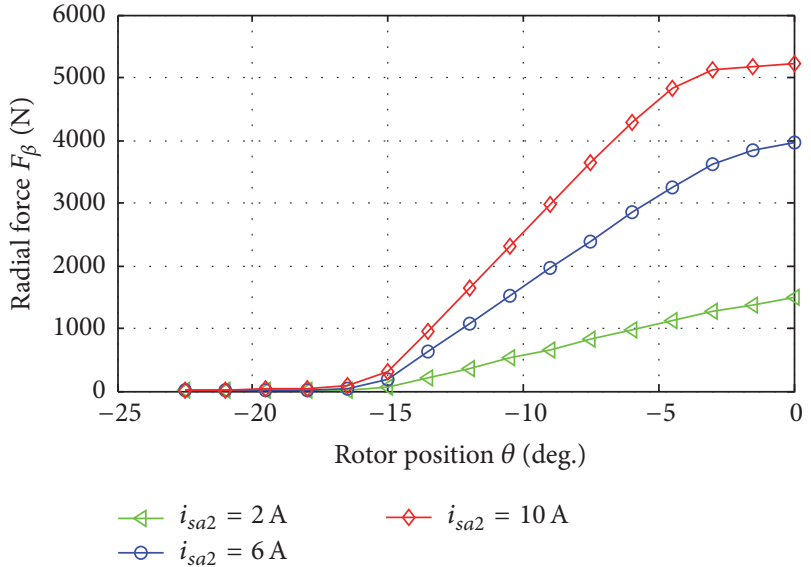

(b)

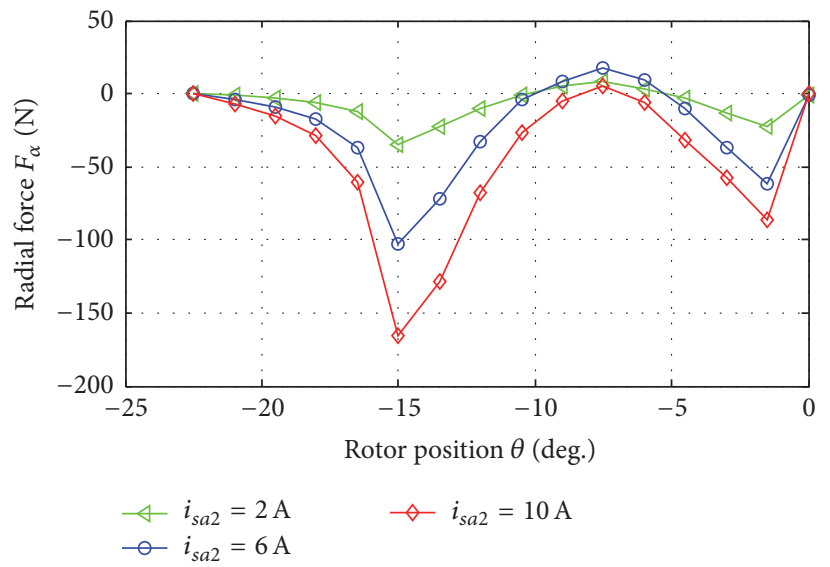

(c)

FIGURE 2: FEA results of torque $T_{e}$ and radial forces $F_{\beta}$ and $F_{\alpha}$ at different rotor positions with different values of $i_{\text {saz }}$ under the conditions $\alpha=\beta=0 \mathrm{~mm}, i_{m a}=10 \mathrm{~A}$, and $i_{s a 1}=0 \mathrm{~A}$. (a) FEA results of $T_{e}$. (b) FEA results of $F_{\beta}$. (c) FEA results of $F_{\alpha}$.

From (5)-(8), the state equation of dual-winding BSRM is a six-order nonlinear system with three inputs and three outputs, and its reversibility must be justified.

When analyzing the reversibility of the system, the first step is to take the derivative of output $\mathbf{y}=\left[y_{1}, y_{2}, y_{3}\right]^{\mathrm{T}}=$ $[\alpha, \beta, \omega]^{\mathrm{T}}$ with respect to time until the components of $\mathbf{u}=$ $\left[u_{1}, u_{2}, u_{3}\right]^{\mathrm{T}}=\left[i_{s a 1}, i_{s a 2}, i_{m a}\right]^{\mathrm{T}}$ are explicitly included [28]. Then, we can obtain

$$
\begin{aligned}
\mathbf{J}(\mathbf{u}) & =\left[\begin{array}{c}
\ddot{y}_{1} \\
\ddot{y}_{2} \\
\dot{y}_{3}
\end{array}\right] \\
& =\left[\begin{array}{c}
\frac{1}{m}\left[u_{3}\left(K_{f 1} \cdot u_{1}-K_{f 2} \cdot u_{2}\right)\right] \\
\frac{1}{m}\left[u_{3}\left(K_{f 2} \cdot u_{1}-K_{f 1} \cdot u_{2}\right)\right]-g \\
\frac{1}{J}\left[K_{t}\left(2 N_{m}^{2} u_{3}^{2}+N_{s}^{2} u_{1}^{2}+N_{s}^{2} u_{2}^{2}\right)-T_{L}\right]
\end{array}\right] .
\end{aligned}
$$

Taking the derivative of $\mathbf{J}(\mathbf{u})$, we further obtain the Jacobi matrix $\mathbf{A}$ as follows:

$$
\mathbf{A}=\left[\begin{array}{lll}
\frac{\partial \ddot{y}_{1}}{\partial u_{1}} & \frac{\partial \ddot{y}_{1}}{\partial u_{2}} & \frac{\partial \ddot{y}_{1}}{\partial u_{3}} \\
\frac{\partial \ddot{y}_{2}}{\partial u_{1}} & \frac{\partial \ddot{y}_{2}}{\partial u_{2}} & \frac{\partial \ddot{y}_{2}}{\partial u_{3}} \\
\frac{\partial \dot{y}_{3}}{\partial u_{1}} & \frac{\partial \dot{y}_{3}}{\partial u_{2}} & \frac{\partial \dot{y}_{3}}{\partial u_{3}}
\end{array}\right]
$$

Including (9) into (10), the Jacobi matrix $\mathbf{A}$ can be resolved as

$$
\mathbf{A}=\left[\begin{array}{ccc}
\frac{K_{f 1} u_{3}}{m} & \frac{-K_{f 2} u_{3}}{m} & \frac{K_{f 1} u_{1}-K_{f 2} u_{2}}{m} \\
\frac{K_{f 2} u_{3}}{m} & \frac{K_{f 1} u_{3}}{m} & \frac{K_{f 2} u_{1}+K_{f 1} u_{2}}{m} \\
\frac{2 K_{t} N_{s}^{2} u_{1}}{J} & \frac{2 K_{t} N_{s}^{2} u_{2}}{J} & \frac{4 K_{t} N_{m}^{2} u_{3}}{J}
\end{array}\right] .
$$

Hence,

$\operatorname{det}(\mathbf{A})$

$$
=\frac{2 K_{t}\left(K_{f 1}^{2}+K_{f 2}^{2}\right)}{J m^{2}} u_{3}\left(2 N_{m}^{2} u_{3}^{2}-N_{s}^{2} u_{1}^{2}-N_{s}^{2} u_{2}^{2}\right) .
$$


Obviously, $2 K_{t}\left(K_{f 1}^{2}+K_{f 2}^{2}\right) / J m^{2} \neq 0$. Therefore, if $u_{3} \neq 0$ and $2 N_{m}^{2} u_{3}^{2}-N_{s}^{2} u_{1}^{2}-N_{s}^{2} u_{2}^{2} \neq 0$, that is, if $i_{m a} \neq 0$ and $i_{m a}^{2} \neq\left(N_{s}^{2} i_{s a 1}^{2}+N_{s}^{2} i_{s a 2}^{2}\right) /\left(2 N_{m}^{2}\right)$, then the inequality $\operatorname{det}(\mathbf{A}) \neq 0$ always holds, and the relative order is $\boldsymbol{\alpha}=\left[\alpha_{1}, \alpha_{2}, \alpha_{3}\right]=$ $[2,2,1]$, which satisfies $\alpha_{1}+\alpha_{2}+\alpha_{3}=5 \leq n$ ( $n$ is the number of the state variables defined in (5)). According to inverse system theory [28], the system is reversible. Contrarily, if $i_{m a}=0$ or $i_{m a}^{2}=\left(N_{s}^{2} i_{s a 1}^{2}+N_{s}^{2} i_{s a 2}^{2}\right) /\left(2 N_{m}^{2}\right)$, then the system is irreversible. Thus, the mathematical model of dual-winding BSRM is not completely reversible. The working area can be divided into reversible domain $\mathbf{D}$ and irreversible domain $\widetilde{\mathbf{D}}$.

$$
\begin{aligned}
& \mathbf{D}=\left\{i_{m a} \neq 0, i_{m a}^{2} \neq \frac{N_{s}^{2} i_{s a 1}^{2}+N_{s}^{2} i_{s a 2}^{2}}{2 N_{m}^{2}}\right\} \\
& \widetilde{\mathbf{D}}=\left\{i_{m a}=0 \text { or } i_{m a}^{2}=\frac{N_{s}^{2} i_{s a 1}^{2}+N_{s}^{2} i_{s a 2}^{2}}{2 N_{m}^{2}}\right\} .
\end{aligned}
$$

To realize the decoupling control of dual-winding BSRM, the control scheme should be designed in both reversible domain $\mathrm{D}$ and irreversible domain $\widetilde{\mathbf{D}}$.

3.2. Inversion in the Reversible Domain. From (13), the inequality of $i_{m a} \neq 0$ always holds when dual-winding BSRM is working in reversible domain $\mathbf{D}$. According to the first two equations of the equations set in (4), we can obtain

$$
\begin{aligned}
& i_{s a 1}=\frac{m\left(K_{f 1} \ddot{\alpha}+K_{f 2} \ddot{\beta}+g K_{f 2}\right)}{\left(K_{f 1}^{2}+K_{f 2}^{2}\right) i_{m a}}, \\
& i_{s a 2}=\frac{m\left(K_{f 1} \ddot{\beta}-K_{f 2} \ddot{\alpha}+g K_{f 1}\right)}{\left(K_{f 1}^{2}+K_{f 2}^{2}\right) i_{m a}} .
\end{aligned}
$$

Then, integrating (14) into the third equation of the equations set in (4) gives

$$
\begin{aligned}
& 2 N_{m}^{2} i_{m a}^{4}-\frac{J \dot{\omega}+T_{L}}{K_{t}} i_{m a}^{2}+\frac{N_{s}^{2} m^{2}}{K_{f 1}^{2}+K_{f 2}^{2}}\left[\ddot{\alpha}^{2}+(g+\ddot{\beta})^{2}\right] \\
& \quad=0 .
\end{aligned}
$$

Accordingly, the discriminant of the quadratic equation (15) can be given by

$$
\Delta=\left(\frac{J \dot{\omega}+T_{L}}{K_{t}}\right)^{2}-\frac{8 m^{2} N_{m}^{2} N_{s}^{2}}{K_{f 1}^{2}+K_{f 2}^{2}}\left[\ddot{\alpha}^{2}+(g+\ddot{\beta})^{2}\right] .
$$

Considering that (15) is a unary quadratic equation and its discriminant $\Delta \geq 0$ always holds, its roots exist undoubtedly according to the implicit function theorem. The two roots of (15) can be described as follows:

$$
i_{m a 1,2}^{2}=\frac{1}{4 N_{m}^{2}}\left(\frac{J \dot{\omega}+T_{L}}{K_{t}} \pm \sqrt{\Delta}\right) .
$$

In an actual system, if the value of torque winding current $i_{m a}$ is small, then the bias magnetic field in dual-winding BSRM will be weak, which is unsatisfactory to generate continuous radial force. Hence, the value of torque winding current $i_{m a}$ is selected as

$$
i_{m a}=\frac{1}{2 N_{m}} \sqrt{\frac{J \dot{\omega}+T_{L}}{K_{t}}+\sqrt{\Delta}} .
$$

Then, substituting (18) into (14), the values of suspending winding currents $i_{s a 1}$ and $i_{s a 2}$ can be calculated as follows:

$$
\begin{aligned}
& i_{s a 1}=\frac{2 m N_{m}\left(K_{f 1} \ddot{\alpha}+K_{f 2} \ddot{\beta}+g K_{f 2}\right)}{\left(K_{f 1}^{2}+K_{f 2}^{2}\right) \sqrt{\left[\left(J \dot{\omega}+T_{L}\right) / K_{t}\right]+\sqrt{\Delta}}}, \\
& i_{s a 2}=\frac{2 m N_{m}\left(K_{f 1} \ddot{\beta}-K_{f 2} \ddot{\alpha}+g K_{f 1}\right)}{\left(K_{f 1}^{2}+K_{f 2}^{2}\right) \sqrt{\left[\left(J \dot{\omega}+T_{L}\right) / K_{t}\right]+\sqrt{\Delta}}} .
\end{aligned}
$$

According to inverse system theory [28], we define the new input variables $\left[\varphi_{1}, \varphi_{2}, \varphi_{3}\right]^{\mathrm{T}}=\left[\ddot{y}_{d 1}, \ddot{y}_{d 2}, \dot{y}_{d 3}\right]^{\mathrm{T}}$; here, $y_{d i}(i=$ $1,2,3)$ denotes the desired outputs. By substituting variables $\left[\varphi_{1}, \varphi_{2}, \varphi_{3}\right]^{\mathrm{T}}$ for $\left[\ddot{y}_{1}, \ddot{y}_{2}, \dot{y}_{3}\right]^{\mathrm{T}}$, we can obtain the current-mode inversion of dual-winding BSRM in reversible domain $\mathbf{D}$ as

$$
\begin{aligned}
& u_{1}=\frac{2 m N_{m}\left(K_{f 1} \varphi_{1}+K_{f 2} \varphi_{2}+g K_{f 2}\right)}{\left(K_{f 1}^{2}+K_{f 2}^{2}\right) \sqrt{\left[\left(J \varphi_{3}+T_{L}\right) / K_{t}\right]+\sqrt{\Delta}}}, \\
& u_{2}=\frac{2 m N_{m}\left(K_{f 1} \varphi_{2}-K_{f 2} \varphi_{1}+g K_{f 1}\right)}{\left(K_{f 1}^{2}+K_{f 2}^{2}\right) \sqrt{\left[\left(J \varphi_{3}+T_{L}\right) / K_{t}\right]+\sqrt{\Delta}}}, \\
& u_{3}=\frac{\sqrt{\left[\left(J \varphi_{3}+T_{L}\right) / K_{t}\right]+\sqrt{\Delta}}}{\left(2 N_{m}\right)} .
\end{aligned}
$$

3.3. Improved Inversion in the Irreversible Domain. According to (13), the irreversible domain of dual-winding BSRM includes the following two parts:

$$
\widetilde{\mathbf{D}}=\left\{\begin{array}{l}
\widetilde{\mathbf{D}}_{1}=\left\{i_{m a}=0\right\} \\
\widetilde{\mathbf{D}}_{2}=\left\{i_{m a}^{2}=\frac{N_{s}^{2} i_{s a 1}^{2}+N_{s}^{2} i_{s a 2}^{2}}{2 N_{m}^{2}}\right\} .
\end{array}\right.
$$

(I) In the first part of irreversible domain $\widetilde{\mathbf{D}}_{1}$, substituting the equality of $i_{m a}=0$ into (4) yields

$$
\begin{aligned}
& \ddot{\alpha}=0, \\
& \ddot{\beta}=-g .
\end{aligned}
$$

From (22), the rotor will be in free fall when $i_{m a}=0$, because no bias magnetic field is present to generate radial force for balancing rotor gravity. From the radial force production principle of dual-winding BSRM, a bias magnetic field must exist in the dual-winding BSRM to produce radial force, and, thus, current $i_{m a}$ cannot be zero. The first part of irreversible domain deduced by the theoretical analysis does not exist in 
the actual system. Therefore, it does not have to be considered in decoupling control.

(II) In the second part of irreversible domain $\widetilde{\mathbf{D}}_{2}$, equality $i_{m a}^{2}=\left(N_{s}^{2} i_{s a 1}^{2}+N_{s}^{2} i_{s a 2}^{2}\right) /\left(2 N_{m}^{2}\right)$ always holds. Therefore, the discriminant of (16) equals zero (i.e., $\Delta=0$ ).

$$
\left(\frac{J \dot{\omega}+T_{L}}{K_{t}}\right)^{2}=\frac{8 m^{2} N_{m}^{2} N_{s}^{2}}{K_{f 1}^{2}+K_{f 2}^{2}}\left[\ddot{\alpha}^{2}+(g+\ddot{\beta})^{2}\right] .
$$

From the deduction of (23), equality (23) always holds when the dual-winding BSRM is working in the irreversible domain; from the inverse deduction of (23), if equality (23) holds, then the dual-winding BSRM will work in the irreversible domain. The dual-winding BSRM working in the irreversible domain is equivalent to equality (23) holding; that is, equality $i_{m a}^{2}=\left(N_{s}^{2} i_{s a 1}^{2}+N_{s}^{2} i_{s a 2}^{2}\right) /\left(2 N_{m}^{2}\right)$ is equivalent to (23). Based on this equivalence, the improved inverse system method can be proposed as the following two steps. Firstly, we can multiply modifying factors, the value of which approximately is equal to one, to the feedback variables of $\ddot{\alpha}, \ddot{\beta}$, and $\dot{\omega}$ in (23), respectively, to make Equality (23) not hold, that is, to make the working area from irreversible domain to reversible domain. Secondly, the inverse system method can be adopted in the irreversible domain. In the first step, modifying three feedback variables of $\ddot{\alpha}, \ddot{\beta}$, and $\dot{\omega}$ simultaneously is difficult. To avoid this problem, $\ddot{\beta}$ is selected to multiply modified factor $K_{\beta}$ to build the improved inversion in this study. By multiplying modified factor $K_{\beta}$ by $\ddot{\beta}$, we can obtain the following inequality:

$$
\left(\frac{J \dot{\omega}+T_{L}}{K_{t}}\right)^{2} \neq \frac{8 m^{2} N_{m}^{2} N_{s}^{2}}{K_{f 1}^{2}+K_{f 2}^{2}}\left[\ddot{\alpha}^{2}+\left(g+K_{\beta} \ddot{\beta}\right)^{2}\right] .
$$

Hence, the working area of dual-winding BSRM is changed from the irreversible domain to the reversible domain. Then, substituting $K_{\beta} \ddot{\beta}$ for $\ddot{\beta}$ to (19), that is, substituting $K_{\beta} \varphi_{2}$ for $\varphi_{2}$ to (20), the improved inversion of the dual-winding BSRM in the irreversible domain can be given as

$$
\begin{aligned}
& u_{1}=\frac{2 m N_{m}\left(K_{f 1} \varphi_{1}+K_{f 2} K_{\beta} \varphi_{2}+g K_{f 2}\right)}{\left(K_{f 1}^{2}+K_{f 2}^{2}\right) \sqrt{\left[\left(J \varphi_{3}+T_{L}\right) / K_{t}\right]+\sqrt{\Delta^{\prime}}}}, \\
& u_{2}=\frac{2 m N_{m}\left(K_{f 1} K_{\beta} \varphi_{2}-K_{f 2} \varphi_{1}+g K_{f 1}\right)}{\left(K_{f 1}^{2}+K_{f 2}^{2}\right) \sqrt{\left[\left(J \varphi_{3}+T_{L}\right) / K_{t}\right]+\sqrt{\Delta^{\prime}}}}, \\
& u_{3}=\frac{\sqrt{\left[\left(J \varphi_{3}+T_{L}\right) / K_{t}\right]+\sqrt{\Delta^{\prime}}}}{\left(2 N_{m}\right)},
\end{aligned}
$$

where $\Delta^{\prime}=\left(\left(J \varphi_{3}+T_{L}\right) / K_{t}\right)^{2}-\left(8 m^{2} N_{m}^{2} N_{s}^{2} /\left(K_{f 1}^{2}+K_{f 2}^{2}\right)\right)\left[\varphi_{1}^{2}+\right.$ $\left.\left(g+K_{\beta} \varphi_{2}\right)^{2}\right]$.

In comparing the improved inversion (25) in the irreversible domain with the inversion (20) in the reversible domain, the improved inverse system method involves changing the working area of dual-winding BSRM from the irreversible domain to the reversible domain by modifying the feedback values of the control object and then adopting the traditional inverse system to realize the decoupling control of the dual-winding BSRM in irreversible domain. In addition, inversion (20) is a special case of $K_{\beta}=1$ of the improved inversion (25). Hence, the improved inverse system method is more universal and efficient than the traditional one, and it can be applied to the irreversible system.

3.4. Design of Robust Servo Regulator. According to inverse system theory [28], by connecting the improved inversion (25) before dual-winding BSRM, it can be linearized and decoupled to two second-order integral type displacement subsystems and one first-order integral type speed subsystem. The transfer functions are as follows:

$$
\mathbf{G}(\mathbf{s})=\left[G_{\alpha}(s), G_{\beta}(s), G_{\omega}(s)\right]^{\mathrm{T}}=\left[\frac{1}{s^{2}}, \frac{1}{s^{2}}, \frac{1}{s}\right]^{\mathrm{T}} .
$$

However, these transfer functions (26) are the nominal model of three pseudo-linear subsystems. Practically, considering the uncertainty of parameters and model errors, the composition of the dual-winding BSRM and its improved inversion (25) is not exactly equivalent to the linear subsystem (26). Decoupled plants should be combined with robust controllers because the remaining coupling and nonlinearity always exist. Robust servo regulator is employed in this study given its excellent tracking and robust performance [21], which consists of servo compensator $T(s)$ and stabilizing compensator $K(s)$.

As for the displacement subsystems, their transfer functions can be described as $G_{\alpha}(s)=G_{\beta}(s)=s^{-2}$. According to the design method of robust servo regulator, we let $T_{1}(s)=$ $T_{2}(s)=\left(a_{0}+a_{1} s\right) / s$ and $K_{1}(s)=K_{2}(s)=k_{0}+k_{1} s$. Then, the closed-loop transfer function of the displacement subsystems can be described as

$$
\Phi(s)=\frac{a_{1} s+a_{0}}{s\left(s^{2}+k_{1} s+k_{0}\right)} .
$$

To simplify the selection of the controller parameters, we can design the system that comprises a pair of complex-number dominant poles, and the other poles are far away from the imaginary axis [21]; that is,

$$
\Phi(s)=\frac{\omega_{n}^{2}(s+\delta)}{(s+\delta)\left(s^{2}+2 \xi \omega_{n} s+\omega_{n}^{2}\right)} .
$$

To improve the system response speed, this study selects $\delta=$ $6, \xi=\sqrt{2} / 2$, and $\omega_{n}=800 \mathrm{rad} / \mathrm{s}$. Combining (27) and (28) yields the regulator parameters

$$
\begin{aligned}
& a_{1}=\omega_{n}^{2}=640,000, \\
& a_{0}=\omega_{n}^{2} \delta=3,840,000, \\
& k_{1}=2 \xi \omega_{n}+\delta \approx 1137.2, \\
& k_{0}=\omega_{n}^{2}+2 \xi \omega_{n} \delta \approx 646,787.2 .
\end{aligned}
$$

Similarly, for the speed subsystem $G_{\omega}(s)=s^{-1}$, we let $T_{3}(s)=$ $a_{2}\left(s+\delta_{2}\right) / s$ and $k_{3}(s)=0$; here, the value of $a_{2}$ and $\delta_{2}$ 


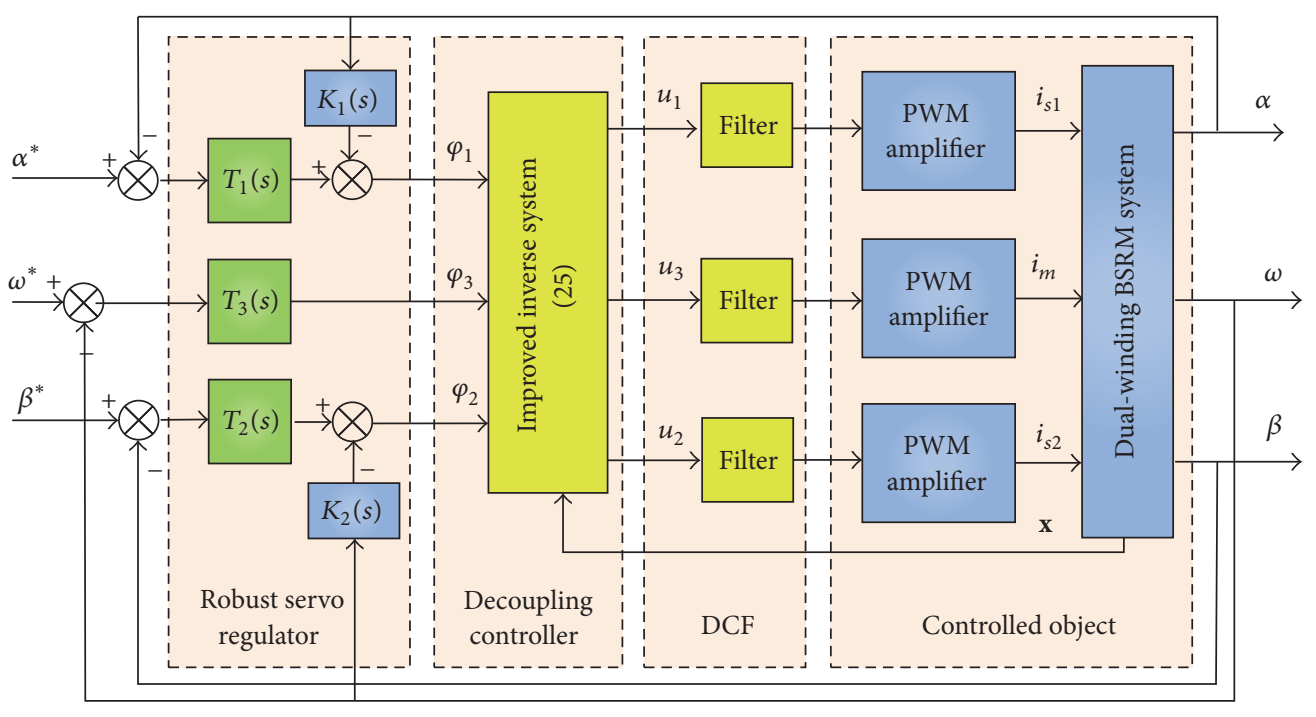

FIGURE 3: Closed-loop compound control system based on robust servo regulator.

is selected by simulations as $a_{2}=1,200$ and $\delta_{2}=6$. The closed-loop transfer function of the speed subsystems can be described as

$$
\Phi(s)=\frac{1,200 s+7,200}{s^{2}+1,200 s+7,200}
$$

The schematic of the closed-loop compound control system based on the improved inverse system and robust servo regulator is shown in Figure 3. According to Figure 3, it is divided into four parts such as robust servo regulator, decoupling controller, DCF, and controlled object. In the controlled object, pulse width modulation (PWM) amplifiers are applied to the torque and suspending windings of the dual-winding BSRM for the torque drive and suspending force. In decoupling controller, by means of current-mode improved inversion equation (25), it is designed and connected before the controlled object so as to realize the linearization and decoupling control. Robust servo regulator consists of servo compensator $T(s)$ and stabilizing compensator $K(s)$ is described as (27)-(30). DCF between the decoupling controller and PWM amplifier in Figure 3 is phase lag dynamic compensation filter, which is designed to improve system stability to achieve 5 high-speed operation, and the design of DCF is described in the next subsection.

\subsection{Design of Dynamic Compensation Filter. Mathematical} model (4) is not dynamically equivalent to actual system because it does not consider the amplifier bandwidth and computation delay. These dynamics can deteriorate decoupling performance and even endanger system stability, especially at high-speed $[26,27]$. One method to solve this issue is introducing compensation filters [29]. The rated speed of dual-winding BSRM is $20,000 \mathrm{r} / \mathrm{min}$; that is, the control bandwidth employed is approximately $333 \mathrm{~Hz}$. To resolve its compensation filter, the frequency response of PWM amplifier is measured via a sine sweep test; the blue thin line in Figure 4 shows the positive frequency phase response curve drawn by an Agilent 35670A dynamic signal analyzer. The phase lag at $333 \mathrm{~Hz}$ is nearly $5^{\circ}$. Generally, the desired phase lag is $45^{\circ}$, and, thus, the phase lag that should be compensated at the rated speed frequency is approximately $40^{\circ}$.

Based on the aforementioned analysis and considering the simplicity of filter realization, a second-order filter is designed, and the transfer function of the designed filter is given as

$$
\Phi(s)=\frac{2.1 s^{2}+3,400 s+4.8 \times 10^{6}}{s^{2}+2,080 s+4.8 \times 10^{6}}
$$

The red thick line in Figure 4 shows the positive frequency phase response curve after phase compensation. The phase lag at the rated speed frequency around $333 \mathrm{~Hz}$ has increased from $5^{\circ}$ to nearly $45^{\circ}$. This trend demonstrates that the relative stability of dual-winding BSRM system can be greatly increased by employing DCF.

\section{Simulation and Experimental Results}

4.1. Experimental Setup. A test machine of a dual-winding BSRM is illustrated in Figure 5, and many extensive experiments have been carried out on this test machine, where dualwinding BSRM uses a 3-degree of freedom (DOF) hybrid magnetic bearing $(\mathrm{HMB})$ to realize 5-DOF active control, and it is controlled by a separate controller. We take 2-DOF dualwinding BSRM as the experimental subject. Two assistant bearings are installed in the test machine, and the average air gap between the rotor shaft and assistant bearing is $0.2 \mathrm{~mm}$. The specifications of dual-winding BSRM are presented in Table 1.

The simulation is developed based on the Sim-PowerSystem and the Simulink of MATLAB. The proposed decoupling control algorithm is implemented in the digital signal processor (DSP) chip TMS320F28335, and the analog-todigital converter 1674 is employed. Both the sampling and 


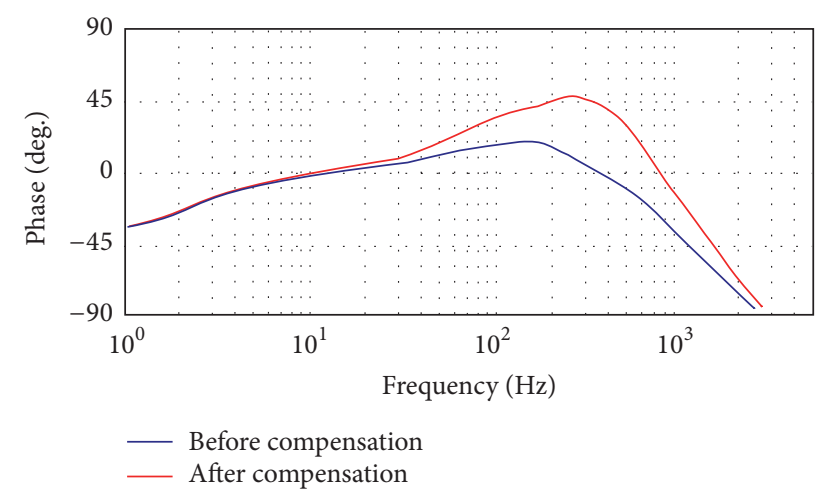

Figure 4: Positive frequency phase response before and after phase compensation.

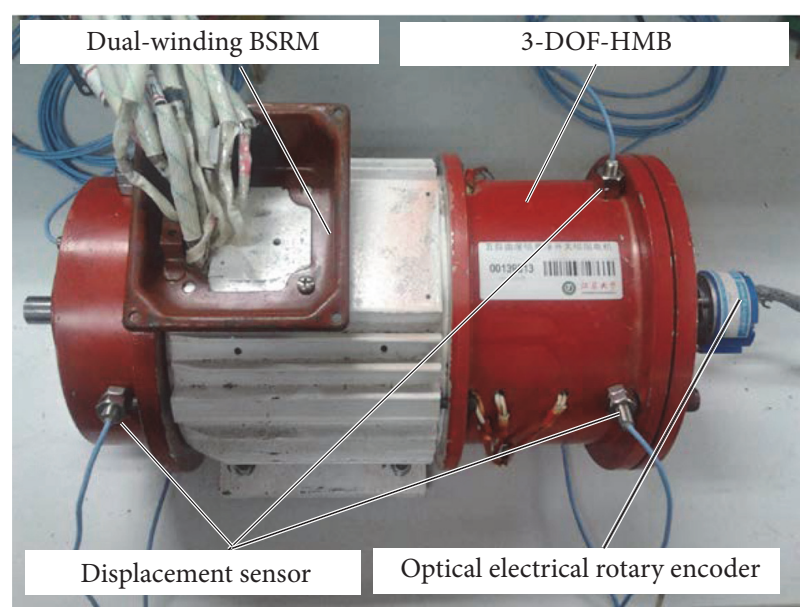

FIGURE 5: Experimental test machine of the dual-winding BSRM.

servo frequency are set to $6.7 \mathrm{kHz}$, and the PWM frequency is $20 \mathrm{kHz}$. In the proposed motor, an incremental optical electrical encoder is employed to be angular position sensor. The displacement sensor is made based on the eddy current principle. Each channel has two displacement sensors. These tools are used to supply rotor eccentric displacement and the phase commutation logic signals and calculate the rotational speed for displacement and speed closed-loop control.

The structure of the entire control system and the flowchart of decoupling control are shown in Figures 3 and 6 , respectively.

According to Figure 3, the radial displacements and rotational speed are compared with the reference values, and the errors are fed to robust servo regulator. The robust servo regulator outputs are then fed to improved inverse system to realize the decoupling, and, through the composition of the DCF, the duty cycles of the PWM are generated. Then the control of dual-winding BSRM can be divided into two independent parts, that is, the torque drive and suspending force. In the part of torque drive, the direct control currents $\mathbf{i}_{\mathbf{m}}$ from PWM amplifier are applied on the torque. Consequently, the torque $T_{e}$ is generated. By means of the rotor motion equation, when the generated torque is
TABLE 1: Specifications of dual-winding BSRM.

\begin{tabular}{lc}
\hline Parameter & Value \\
\hline Rated power of torque winding, $\mathrm{kW}$ & 2 \\
Rated power of suspending winding, $\mathrm{kW}$ & 1 \\
Rated voltage of torque winding, V & 110 \\
Rated voltage of suspending winding, V & 110 \\
Rated speed, r/min & 20,000 \\
Rated frequency, Hz & 333 \\
Torque winding turns, turns & 17 \\
Suspending winding turns, turns & 15 \\
Stator outer diameter, mm & 130 \\
Stator pole arc, deg. & 15 \\
Stator yoke width, mm & 10 \\
Rotor diameter, mm & 60 \\
Rotor pole arc, deg. & 15 \\
Rotor yoke width, mm & 10 \\
Air-gap length, mm & 0.25 \\
Axial stack length, mm & 70 \\
Mass of the rotor, Kg & 1 \\
Moments of inertia of the rotor, $\mathrm{kg} \cdot \mathrm{m}^{2}$ & $9 \times 10^{-3}$ \\
Stator/rotor core material & $\mathrm{DW} 360 \_50$ \\
\hline
\end{tabular}

TABLE 2: Computer run time of different control methods.

\begin{tabular}{lc}
\hline Method & Computer run time \\
\hline Square-wave currents control [14] & $145.4 \mu \mathrm{s}$ \\
Analytic inverse plus PID control [22] & $98.8 \mu \mathrm{s}$ \\
Neural network inverse control [24] & $425.8 \mu \mathrm{s}$ \\
Support vector machine inverse control [25] & $308.5 \mu \mathrm{s}$ \\
Proposed control method & $99.4 \mu \mathrm{s}$ \\
\hline
\end{tabular}

larger than the load torque $T_{L}$, the rotor can speed up. In the part of suspending force, control currents $\mathbf{i}_{\mathrm{s} 1}$ and $\mathbf{i}_{\mathrm{s} 2}$ are generated by the PWM amplifiers, which are applied on the suspending windings. Then, the suspending control flux from the control currents $\mathbf{i}_{\mathrm{s} 1}$ and $\mathbf{i}_{\mathrm{s} 2}$ is composited with bias flux from the torque winding current $\mathbf{i}_{\mathbf{m}}$. Therefore, resultant flux generated the suspending force.

As shown in Figure 6, the decoupling control flowchart mainly includes four steps. The first step is to establish the mathematical model and analyze its reversibility. The second one is to divide the work area into reversible and irreversible domain based on the model reversibility analysis and construct the inversion and the improved inversion before the controlled object to realize the linearization and decoupling. The third is to design the robust servo regulator and DCF, so as to build the closed-loop compound control system. The fourth step, that is, the last step, is the simulation and experiment research, and in this step the controller parameters should be modified until the control performance requirements are met.

The computer run time of different methods is tested (see Table 2). The computer run time of the proposed method is shorter than those of the square-wave current control, much shorter than those of the neural network inverse and support 


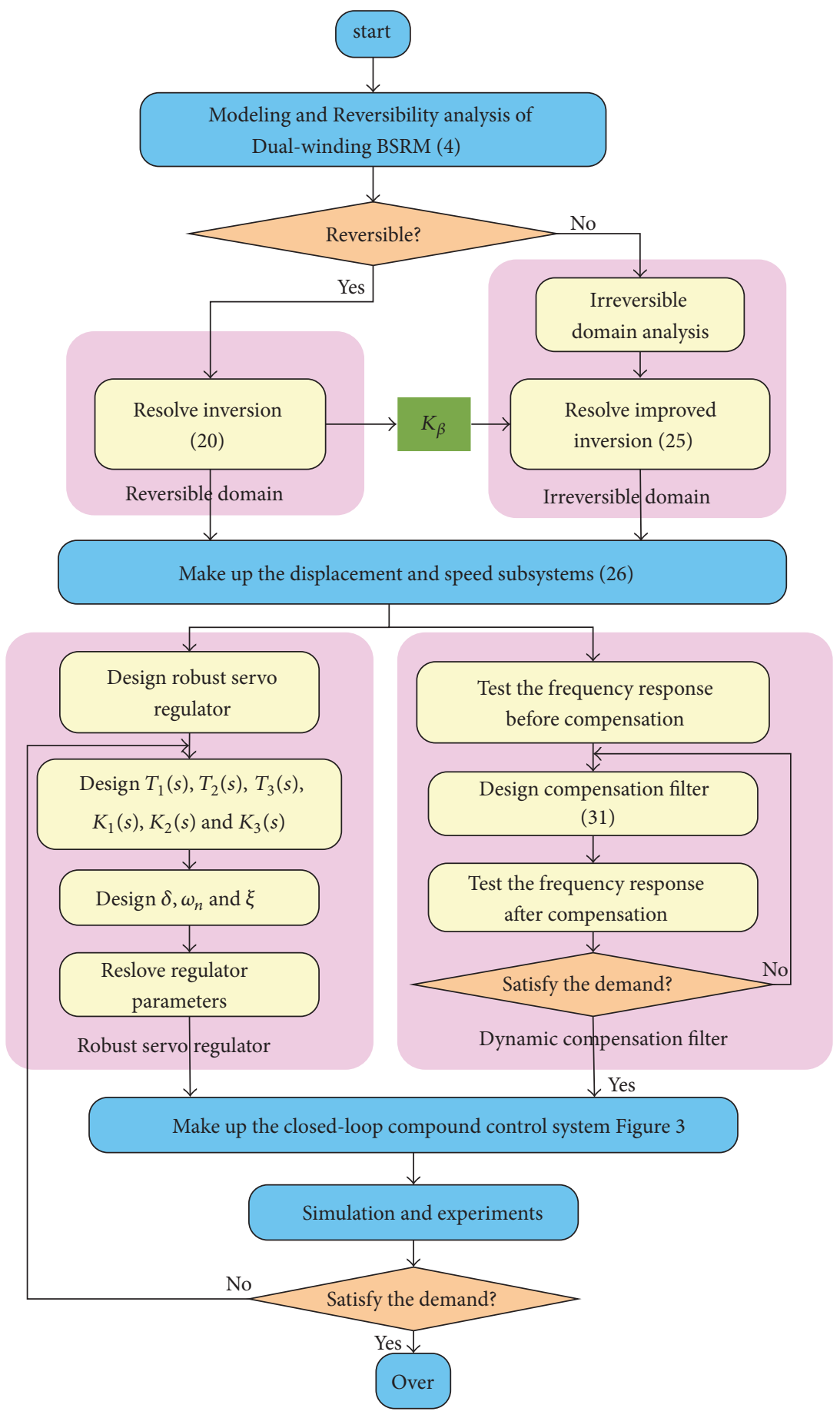

FIgURE 6: Flowchart of decoupling control.

vector machine inverse control methods, and similar to that of the analytic inverse system plus PID control method. Consistent with the analysis in Section 1, this finding indicates that the proposed control method can greatly simplify the industrial realization compared with the square-wave current control and intelligent inverse system decoupling control strategy.

4.2. Decoupling Performance. To further verify the decoupling control performance between the proposed method and the analytic inverse plus PID control [22], hereafter referred to as traditional method, many comparative simulations and experiments have been developed. In the traditional method, as shown in [22], the values of coefficients for displacement-PID and speed-PID are given as $k_{p}=0.32$, $k_{i}=0.2$, and $k_{d}=0.05$ and $k_{r p}=4.3, k_{r i}=1.6$, and $k_{r d}=0.4$, respectively. In this study, the method of choice for PID coefficients in traditional method is skipped. Interested readers are referred to [22] for detailed information. 

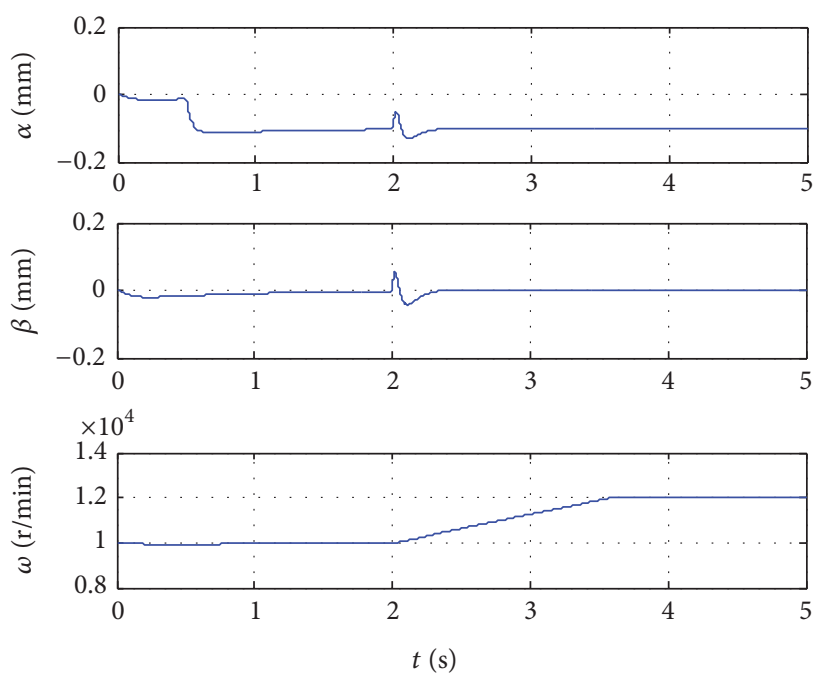

(a)
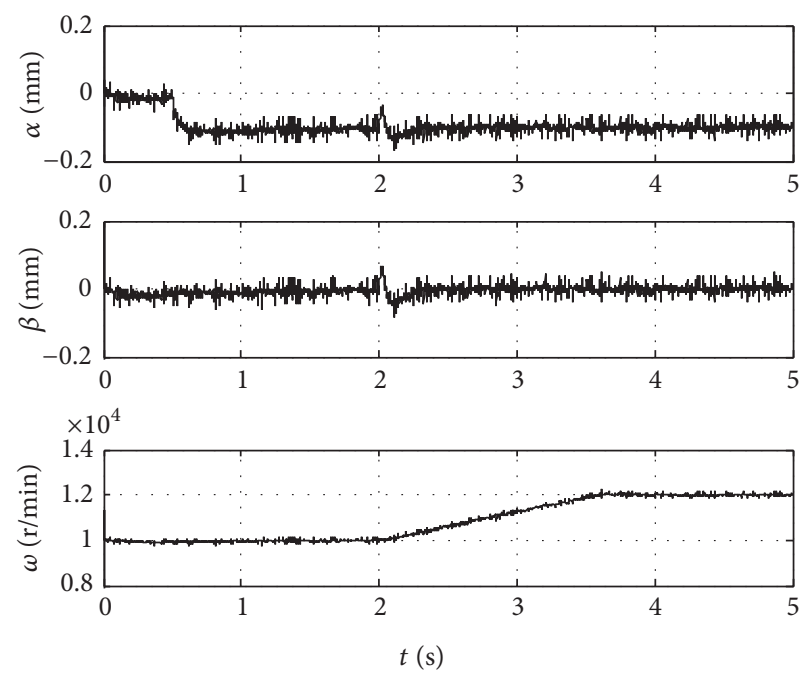

(c)
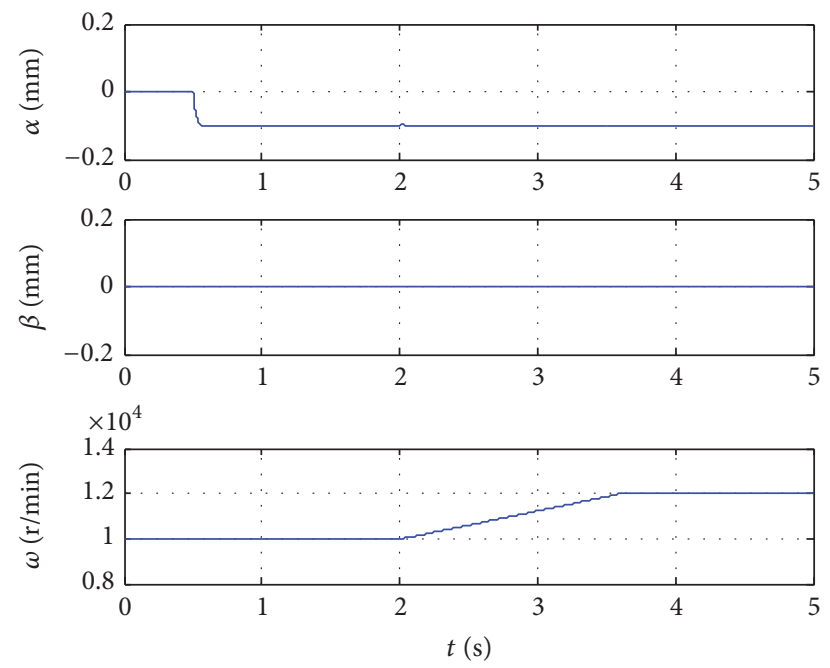

(b)
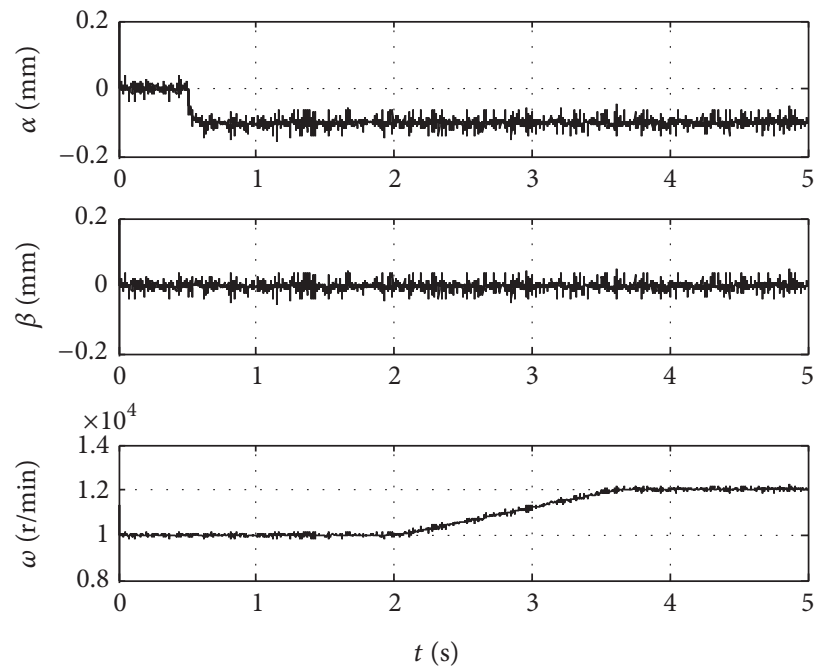

(d)

FIGURE 7: Simulation and experimental comparison of decoupling performance in the reversible domain based on two different control methods. (a) Simulation results by traditional method. (b) Simulation results by the proposed method. (c) Experimental results by traditional method. (d) Experimental results by the proposed method.

4.2.1. Decoupling in the Reversible Domain. In the reversible domain, comparative simulation and experiments between the two different methods have been developed with various rotational speeds and displacements. At time $t=0.5 \mathrm{~s}$, the reference translation displacement $\alpha$ steps from 0 to $-0.1 \mathrm{~mm}$, at time $t=2 \mathrm{~s}$, and the reference rotational speed $\omega$ steps from 10,000 to $12,000 \mathrm{r} / \mathrm{min}$. Figure 7 shows the results of comparative simulation and experiments.

The step of $\alpha$ does not bring a marked effect on $\beta$ and $\omega$ through both the traditional and proposed methods. However, as shown in Figure 7(a), the step of $\omega$ results in distinct fluctuations of approximately 80 and $100 \mu \mathrm{m}$ on $\alpha$ and $\beta$, respectively, with the traditional method, whereas it has slight effect on $\alpha$ and $\beta$ with the proposed control strategy, as shown in Figure 7(b). Similar conclusions can be drawn from the experimental results as shown in Figures $7(\mathrm{c})$ and $7(\mathrm{~d})$. Although the experimental and simulation results slightly vary because of noise and dynamic imbalances, they agree well overall. This conclusion can also be observed in later comparisons.

These results indicate that the traditional method can realize the decoupling between two translation motions, but it cannot completely eliminate the coupling between the rotation and translation motions. That is, the traditional method can only realize the decoupling between the two translation motions but not the decoupling among the rotation and translation motions.

Compared with the traditional method, the proposed one possesses more decoupling DOF.

4.2.2. Decoupling in the Irreversible Domain. To further validate the decoupling performance of the proposed algorithm in the irreversible domain, comparative simulation and experiments of the traditional method and the proposed one 

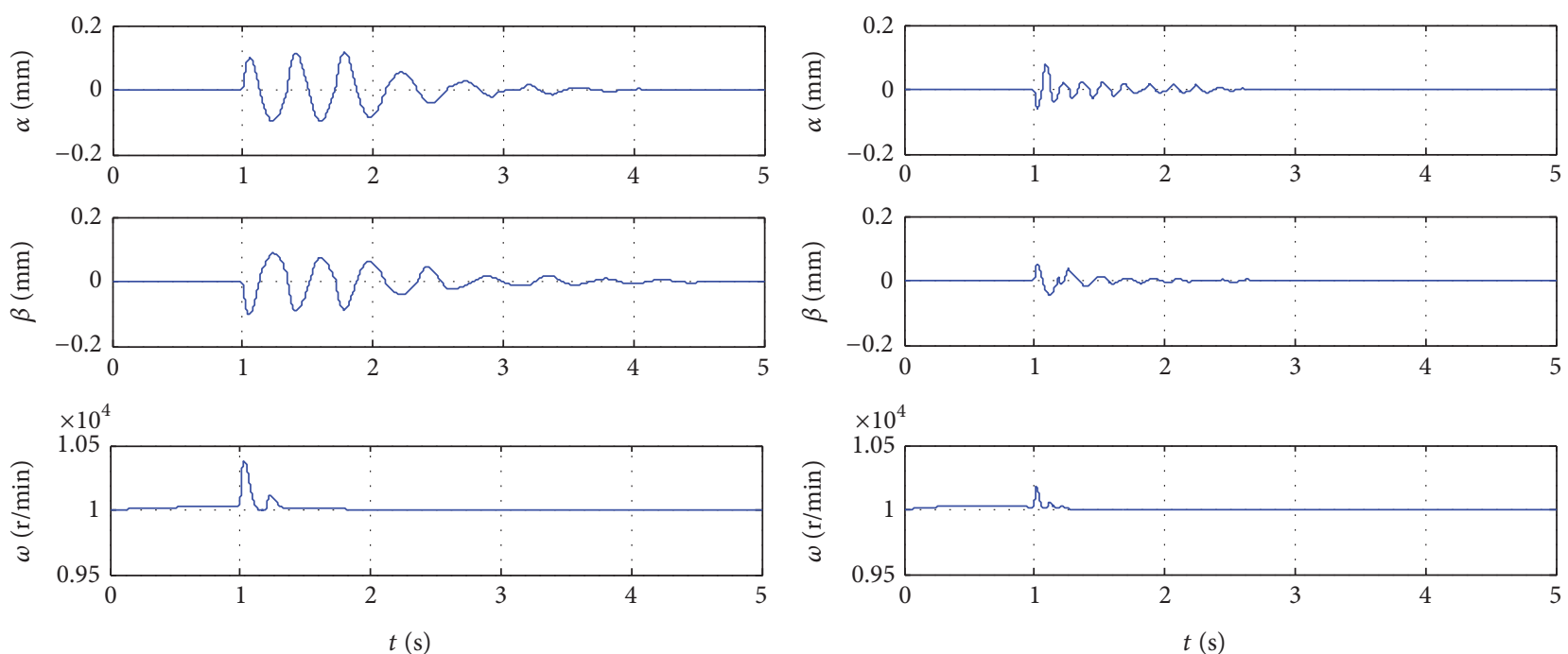

(a)
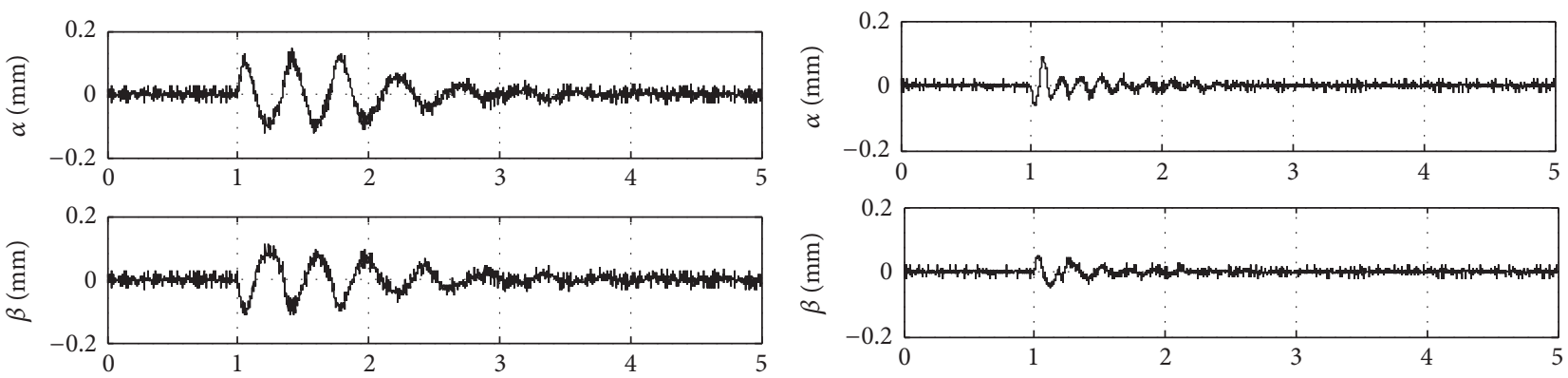

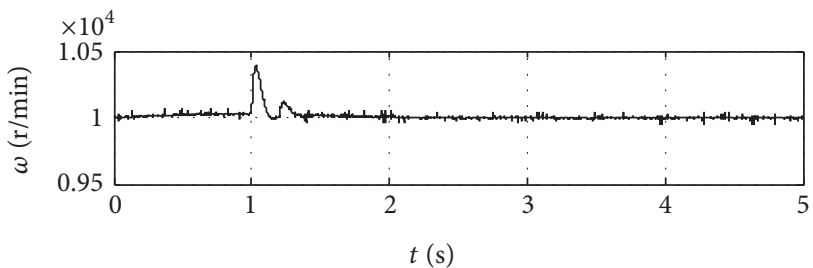

(c)

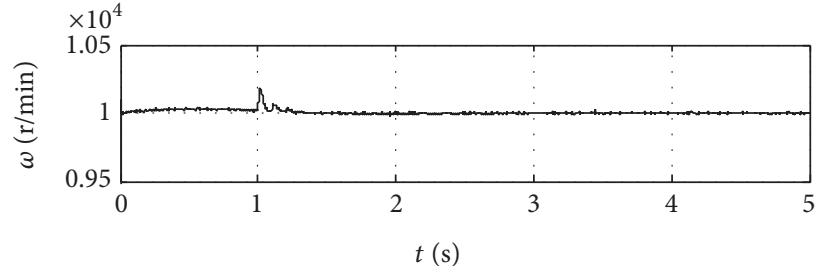

(d)

FIGURE 8: Simulation and experimental comparison of decoupling performance in the irreversible domain based on two different control methods. (a) Simulation results by traditional method. (b) Simulation results by the proposed method. (c) Experimental results by traditional method. (d) Experimental results by the proposed method.

have been carried out under the conditions $\omega=10,000 \mathrm{r} / \mathrm{min}$ and $\alpha=\beta=0$.

The simulation and experimental results by the two methods are shown in Figure 8. As shown in Figure 8(a), when dual-winding BSRM works from reversible domain to irreversible domain at time $t=1 \mathrm{~s}$, significant fluctuations exist as large as approximately $120 \mu \mathrm{m}$ and $100 \mu \mathrm{m}$ on displacement $\alpha$ and displacement $\beta$ as well as roughly $400 \mathrm{r} / \mathrm{min}$ on speed $\omega$ with the traditional method. Strong fluctuations also appear repeatedly as the adjusted time lasts as long as nearly $3 \mathrm{~s}$. By contrast, according to Figure $8(\mathrm{~b})$, when the proposed control method is adopted, the above values of fluctuation are reduced to $80 \mu \mathrm{m}, 50 \mu \mathrm{m}$, and $100 \mathrm{r} / \mathrm{min}$, respectively. Strong fluctuation only appears once because the adjusted time is shortened to $1.5 \mathrm{~s}$, which is roughly $50 \%$ of that in the traditional method. Similar conclusions can be drawn from the experimental results (see Figures $8(\mathrm{c})$ and $8(\mathrm{~d})$ ).

These results indicate that the proposed method has realized the decoupling control of dual-windings BSRM in the irreversible domain, and the control precision of the rotation and translation motions has been improved evidently by adopting the presented strategy.

4.3. Tracking Performance. To demonstrate the tracking performance of the proposed strategy, three different shape signals are utilized to test the tracking precision. In detail, the reference displacement $\alpha$ tracks the sine wave signal $0.1 \sin (2 \pi t+0.2 \pi) \mathrm{mm}$, the reference displacement $\beta$ tracks the sawtooth wave signal $0.1 \operatorname{sawtooth}(2 \pi t) \mathrm{mm}$, and the reference speed $\omega$ steps from 10,000 to $12,000 \mathrm{r} / \mathrm{min}$ at time $t=0.5 \mathrm{~s}$ and then back to $11,000 \mathrm{r} / \mathrm{min}$ at time $t=3.5 \mathrm{~s}$. 

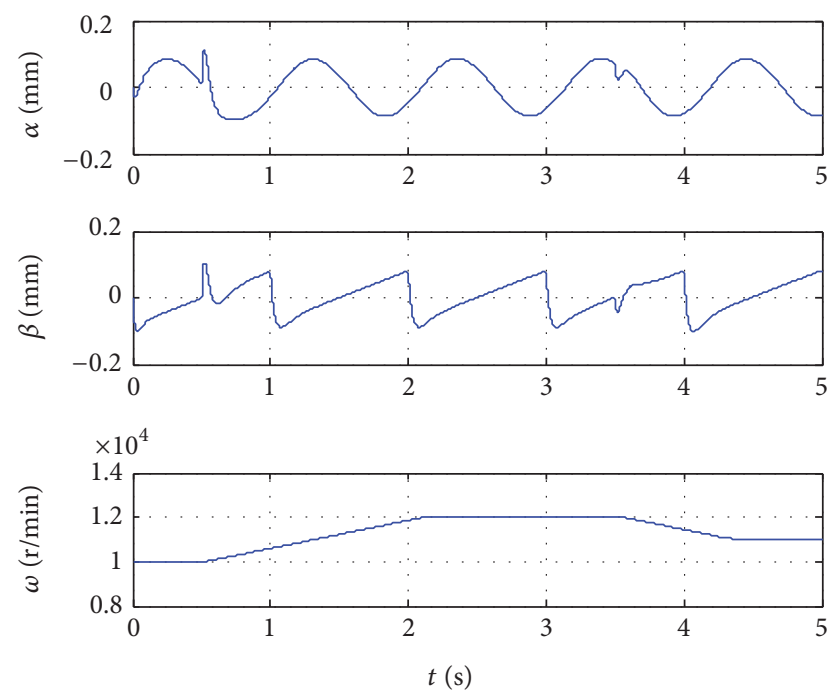

(a)
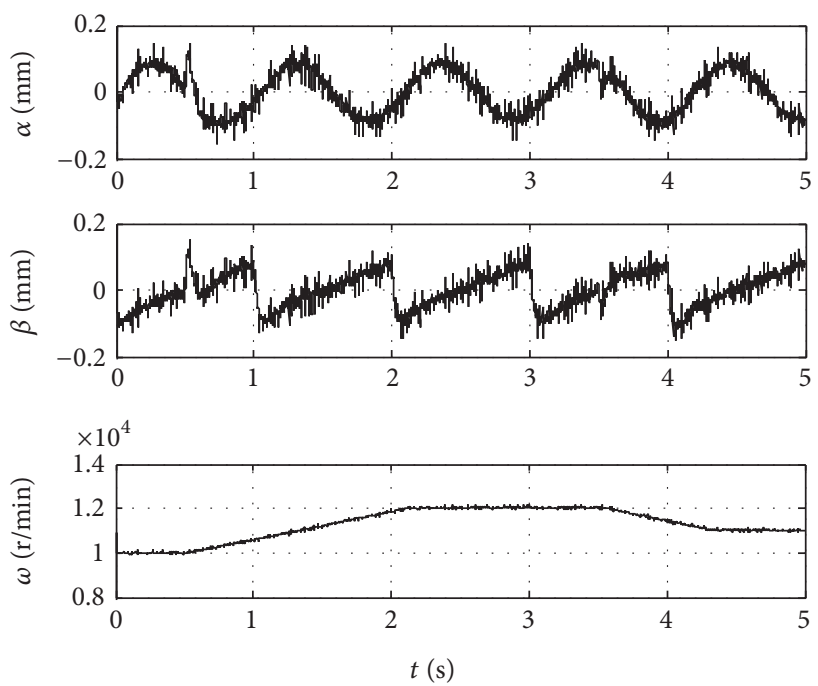

(c)
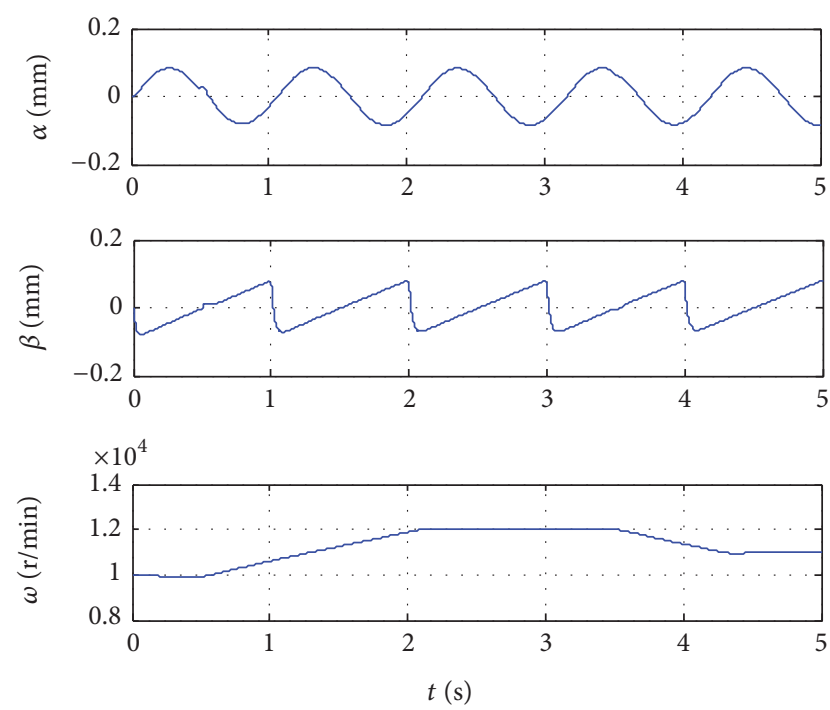

(b)
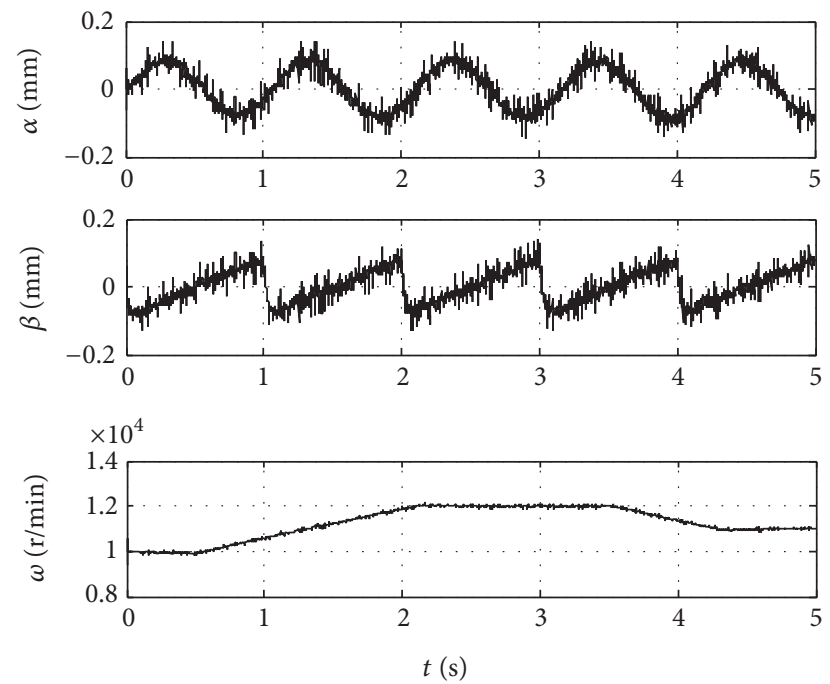

(d)

FIGURE 9: Simulation and experimental comparison of tracking performance based on two different control methods. (a) Simulation results by traditional method. (b) Simulation results by the proposed method. (c) Experimental results by traditional method. (d) Experimental results by the proposed method.

Figure 9 shows the comparative simulation and experimental results between the traditional and the proposed methods.

Figures 9(a) and 9(b) illustrate that both the traditional and the proposed methods do not bring any marked overshoot on speed $\omega$ when reference $\omega$ tracks the step signal, and the accelerating time from 10,000 to $12,000 \mathrm{r} / \mathrm{min}$ is less than $2 \mathrm{~min}$. This finding indicates that the proposed method exhibits a good tracking performance as well as the traditional one.

However, as Figure 9(a) shows, with the traditional method, pulse disturbances exist on $\alpha$ and $\beta$ when $\omega$ tracks the step signal, and the peak amplitude of disturbances on $\alpha$ and $\beta$ are roughly 90 and $100 \mu \mathrm{m}$. By contrast, Figure 9(b) demonstrates that such issue is nonexistent when employing the proposed method, because the decoupling between the translation and rotation motions has been realized by this method, as verified in the last subsection.

Figures 9(a) and 9(b) also show that, at the valley points of the sin wave and the sawtooth wave signals, the proposed method has higher tracking accuracy than the traditional method.

These comparative results further confirm that the presented method show great improvements in terms of tracking performance. Similar conclusions can be drawn from the experimental results (see Figures 9(c) and 9(d)).

4.4. Disturbance Rejection and Robustness Performances. To further verify the robustness performances of the proposed control algorithm, the reference steps, external disturbances, 

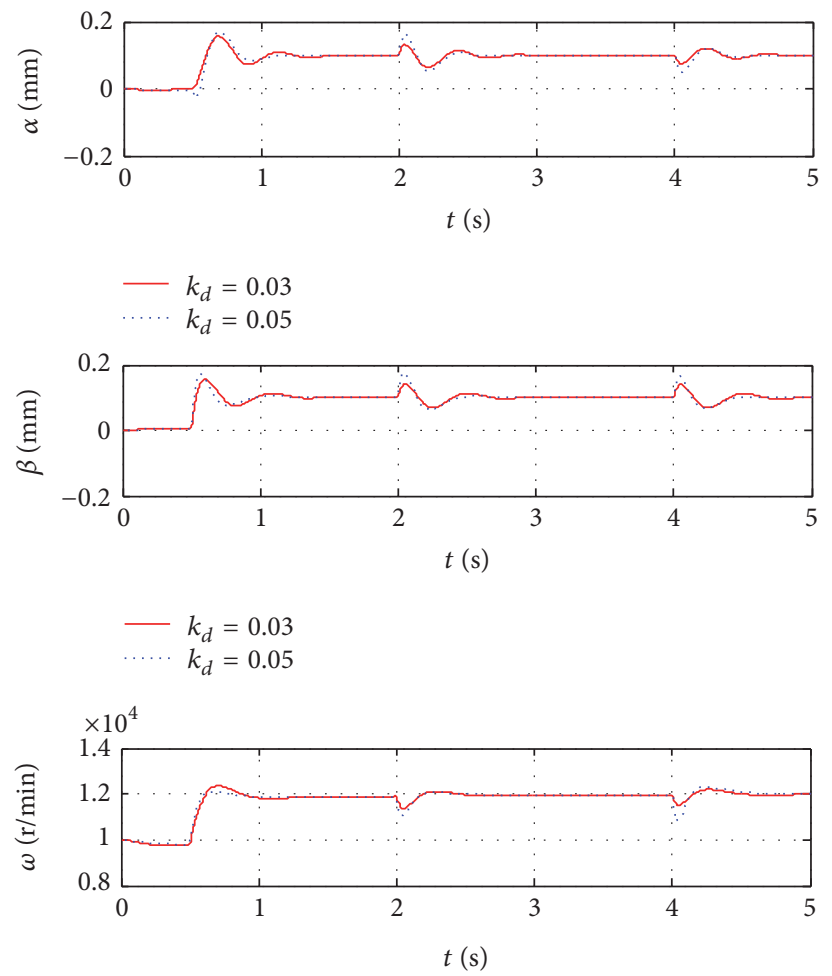

$$
\begin{aligned}
-k_{r d} & =0.1 \\
\cdots \cdots & k_{r d}=0.4
\end{aligned}
$$

(a)
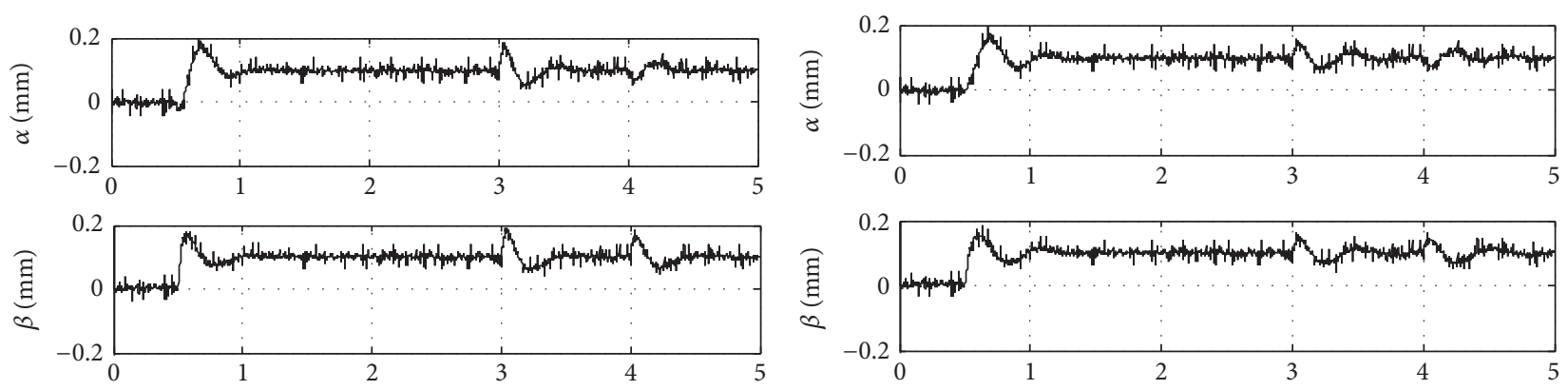

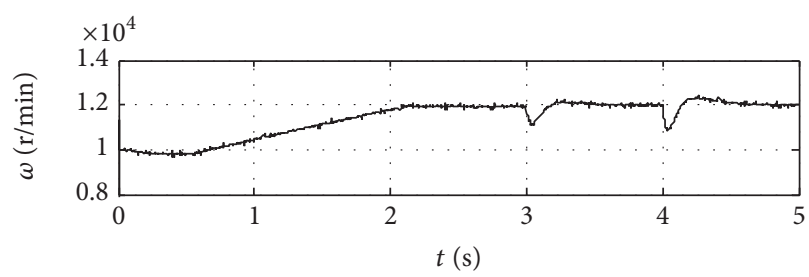

(b)

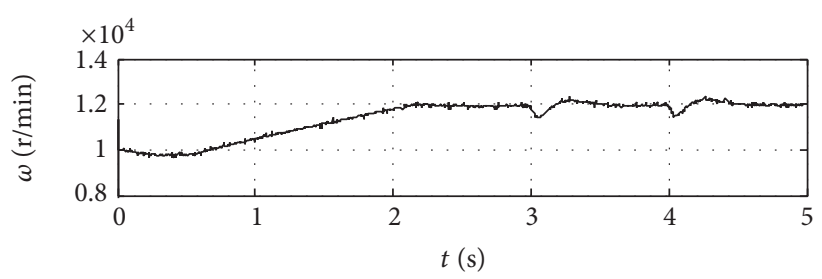

(c)

FIGURE 10: Comparative simulation and experimental results of disturbance rejection and robustness performances of the traditional method with different controller parameters. (a) Comparative simulation results with different values of $k_{d}$ and $k_{r d}$. (b) Experimental results with $k_{d}=$ 0.05 and $k_{r d}=0.4$. (c) Experimental results with $k_{d}=0.03$ and $k_{r d}=0.1$.

and parameter variations are imposed on the system. At time $t=0.5 \mathrm{~s}$, the reference displacement $\alpha$ and displacement $\beta$ step from 0 to $0.1 \mathrm{~mm}$, and the reference speed $\omega$ steps from 10,000 to $12,000 \mathrm{r} / \mathrm{min}$. At time $t=3 \mathrm{~s}$, a radial disturbing force $10 \mathrm{~N}$ and a load torque $-0.8 \mathrm{~N} \cdot \mathrm{m}$ are imposed on the rotor, and, at time $t=4 \mathrm{~s}$, we assume that the coefficients of radial force $K_{f 2}$ increase by $25 \%$ and the coefficients of torque $J_{t}$ decrease by $30 \%$. Comparative simulations and experiments with different values of $k_{d}$ and $k_{r d}$ in the traditional controller and different values of $\xi$ and $\delta_{2}$ in the proposed one are also performed in Figures 10 and 11, respectively. 

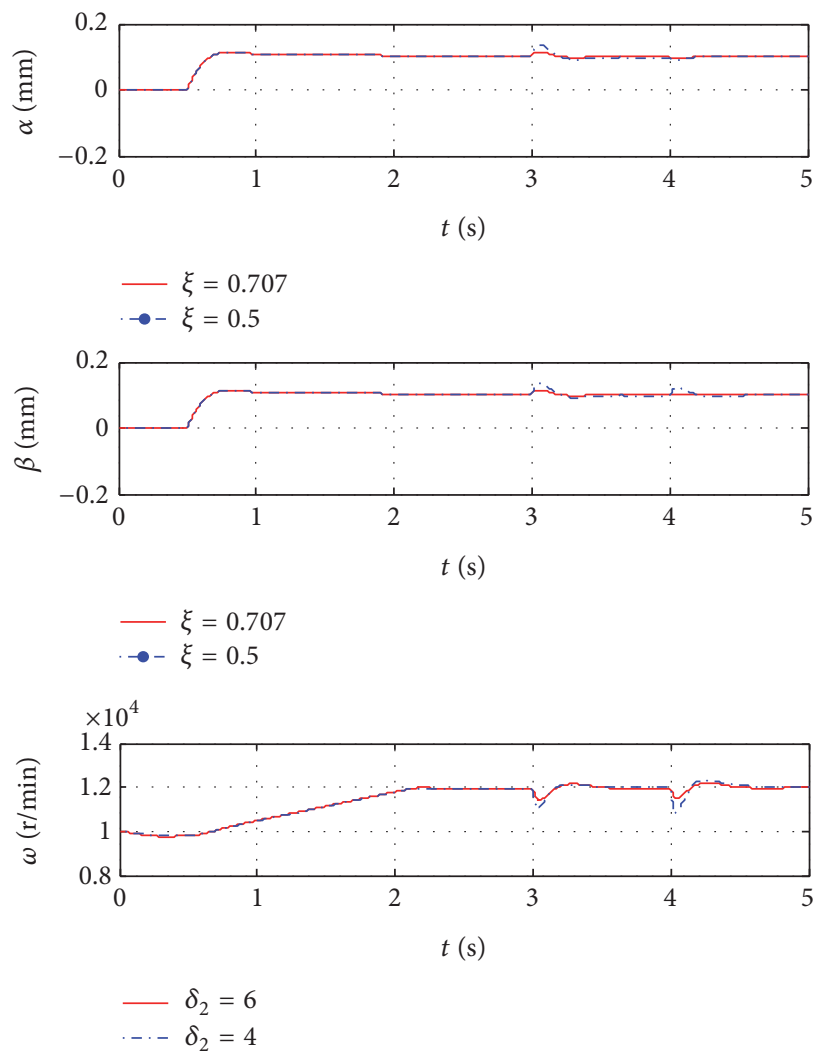

(a)
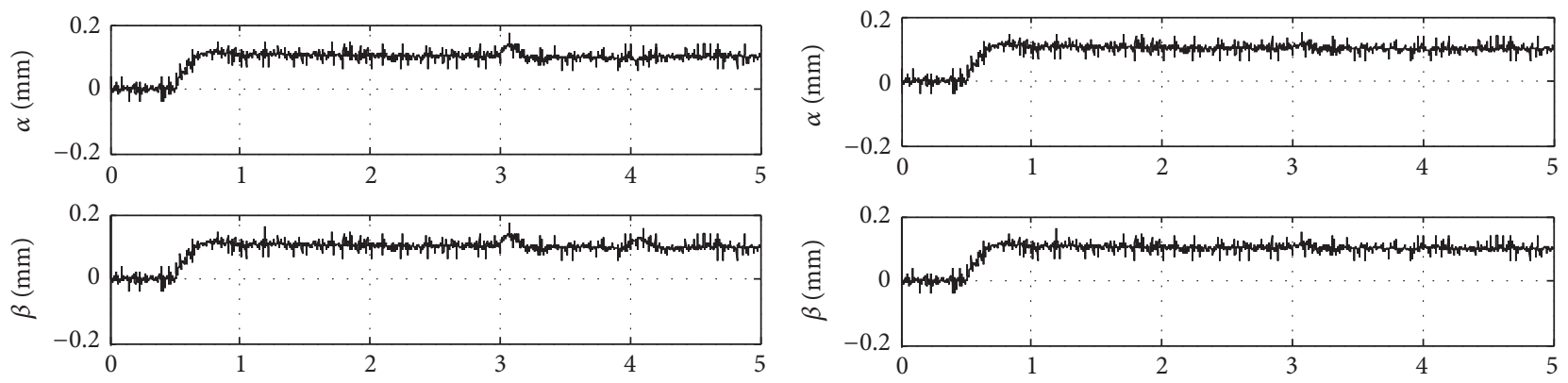

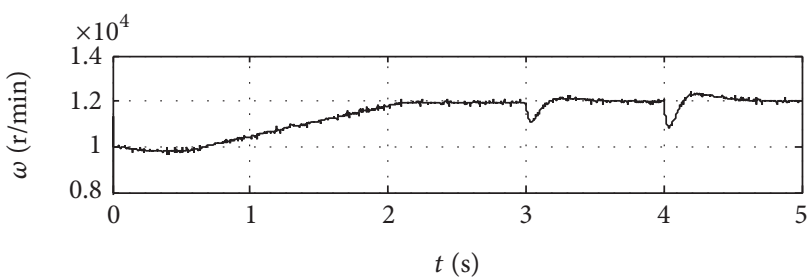

(b)

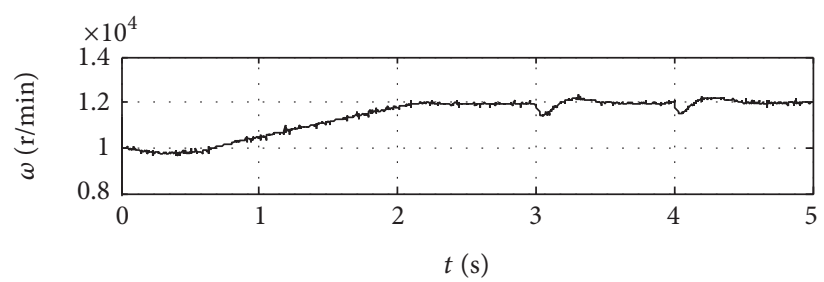

(c)

FiguRE 11: Comparative simulation and experimental results of disturbance rejection and robustness performances of the proposed method with different controller parameters. (a) Comparative simulation results with different values of $\xi$ and $\delta_{2}$. (b) Experimental results with $\xi=0.5$ and $\delta_{2}=4$. (c) Experimental results with $\xi=0.707$ and $\delta_{2}=6$.

From Figure 10(a), for the traditional controller, the external disturbance and parameter variations result in roughly $80 \mu \mathrm{m}, 50 \mu \mathrm{m}$, and $800 \mathrm{r} / \mathrm{min}$ disturbances on $\alpha$, $\beta$, and $\omega$, respectively. Although this outcome has been greatly improved by decreasing the differential coefficients $k_{d}$ (from 0.05 to 0.03 ) and $k_{r d}$ (from 0.4 to 0.1 ), its response time prolongs when tracking the reference displacement or speed. That is, the traditional method cannot adjust the performances of the tracking, disturbance rejection, and robustness independently. Concretely speaking, the decrease of $k_{d}$ and $k_{r d}$ can improve disturbance rejection and robustness performances, but it sacrifices the tracking performance.

By contrast, according to Figure 11(a), with the proposed strategy, the external disturbance and parameter variations 
do not bring obvious disturbances into $\alpha, \beta$, and $\omega$. In addition, the increase of $\xi$ (from 0.5 to 0.707 ) and $\delta_{2}$ (from 4 to 6) can decrease the values of disturbances without any effects on the tracking performance. That is, the proposed control strategy can adjust tracking, disturbance rejection, and robustness performances independently. The experimental results, as shown in Figures 10(b), 10(c), 11(b) and 11(c), further verify the correctness of the simulation.

In conclusion, the traditional control method cannot adjust the control performances of the tracking, disturbance rejection, and robustness independently. Seeking its optimal coefficients is rather difficult. Often, even if the coefficients have been selected, the traditional method cannot satisfy the control performances of the tracking, disturbance rejection, and robustness simultaneously. Contrarily, the proposed control strategy can adjust the control performances of the tracking and robustness independently. Therefore, this method not only simplifies the adjustment of parameters but also improves tracking, disturbance rejection, and robustness performances simultaneously.

\section{Conclusion}

In this study, the model and reversibility analysis of dualwinding BSRM were explored, and a new decoupling control method based on improved inverse system and robust servo regulator was proposed. The following five conclusions can be drawn from this study:

(i) Dual-winding BSRM is a multivariable, high-nonlinear motor with strong coupling, not only between the radial forces but also between the torque and radial forces. It is also an incomplete reversible system, whose working area can be divided into reversible and irreversible domains.

(ii) To generate the radial force for balancing rotor gravity, the main winding current of conducting phase $i_{m a}$ of dual-winding BSRM cannot be zero, so $i_{m a}=0$ in the irreversible domain analysis does not exist in the real system. The decoupling control of dual-winding BSRM in the irreversible domain need not consider the case of $i_{m a}=0$.

(iii) The proposed improved inverse system method involves modifying the state feedback of the controlled system. The traditional inverse method is equivalent to the special case of the modified factor $k_{\beta}=1$ in the improved inverse system, so the improved inverse system is more universal and generalized than the traditional inverse system method.

(iv) Simulation and experimental results confirm that the robustness and stability problems induced by the inverse controller can been successfully solved by introducing robust servo regulator and DCF, and the proposed method exhibits more decoupling DOF, higher precision, better tracking, and stronger disturbance rejection and robustness performances than the traditional one. (v) The improved inverse system method can realize the decoupling control of dual-winding BSRM in both reversible and irreversible domains with a satisfied stability and the static as well as dynamic performance. Hence, the working area of dual-winding BSRM is expended from the reversible domain to both the reversible and irreversible domains by adopting proposed method.

\section{Nomenclature}

\begin{tabular}{|c|c|}
\hline$F_{\alpha}, F_{\beta}:$ & $\begin{array}{l}\text { Radial forces acting on rotor in } \alpha \text { - and } \\
\beta \text {-axis, respectively }\end{array}$ \\
\hline$N_{m}, N_{s}:$ & $\begin{array}{l}\text { Number of turns of torque winding } \\
\text { and suspending winding, respectively }\end{array}$ \\
\hline$\theta:$ & $\begin{array}{l}\text { Rotor position from the aligned } \\
\text { position of exciting phase }\end{array}$ \\
\hline$l:$ & Axial stack length of the iron core \\
\hline$r:$ & Radius of the rotor pole \\
\hline$c:$ & Constant 1.49 \\
\hline$m:$ & Mass of the rotor \\
\hline$\alpha, \beta$ & $\begin{array}{l}\text { Rotor displacements in } \alpha \text {-and } \beta \text {-axis, } \\
\text { respectively }\end{array}$ \\
\hline$T_{L}:$ & Load torque \\
\hline$k_{p}, k_{i}$, and $k_{d}$ : & $\begin{array}{l}\text { Proportional, integral, and differential } \\
\text { coefficients of the displacement-PID } \\
\text { controller in traditional method }\end{array}$ \\
\hline$T_{e}:$ & Electromagnetic torque acting on rotor \\
\hline$i_{m a}, i_{s a 1}$, and $i_{s a 2}$ : & $\begin{array}{l}\text { Currents in A-phase torque winding } \\
\text { and suspending winding, respectively }\end{array}$ \\
\hline $\mathbf{i}_{\mathbf{m}}=\left(i_{m a}, i_{m b}, i_{m c}\right)$ & $\begin{array}{l}\text { Control currents in three-phase torque } \\
\text { windings }\end{array}$ \\
\hline $\mathbf{i}_{\mathbf{s} \mathbf{1}}=\left(i_{s a 1}, i_{s b 1}, i_{s c 1}\right)$ & $\begin{array}{l}\text { Control currents in three-phase } \\
\text { suspending windings in the } \alpha \text {-axis }\end{array}$ \\
\hline $\mathbf{i}_{\mathbf{s} 2}=\left(i_{s a 2}, i_{s b 2}, i_{s c 2}\right):$ & $\begin{array}{l}\text { Control currents in three-phase } \\
\text { suspending windings in the } \beta \text {-axis }\end{array}$ \\
\hline$K_{f 1}, K_{f 2}$, and $K_{t}$ : & $\begin{array}{l}\text { Proportional coefficients of radial force } \\
\text { and torque, respectively }\end{array}$ \\
\hline$\delta:$ & Air-gap length \\
\hline$\mu_{0}:$ & Permeability of vacuum \\
\hline$g:$ & Acceleration of gravity \\
\hline$J:$ & Moments of inertia of the rotor \\
\hline D $\widetilde{D}:$ & $\begin{array}{l}\text { Reversible and irreversible domain, } \\
\text { respectively }\end{array}$ \\
\hline$\omega:$ & $\begin{array}{l}\text { Mechanical angular velocity of the } \\
\text { rotor }\end{array}$ \\
\hline$k_{r p}, k_{r i}$, and $k_{r d}:$ & $\begin{array}{l}\text { Proportional, integral, and differential } \\
\text { coefficients of the speed-PID controller } \\
\text { in traditional method. }\end{array}$ \\
\hline
\end{tabular}

\section{Competing Interests}

The authors declare no conflict of interests regarding the publication of this paper.

\section{Acknowledgments}

The work described in this paper was supported by the National Natural Science Foundation of China (no. 
51507077 and no. 51377074), the Natural Science Research of Higher Education Institutions of Jiangsu Province (no. 15KJB470005), Qing Lan Project of Jiangsu Province (Grant no. [2016] 15), and The Open Research Fund of Jiangsu Collaborative Innovation Center for Smart Distribution Network (Grant no. XTCX201601) as well as foundations sponsored by Nanjing Institute of Technology (no. CKJA201407).

\section{References}

[1] D.-H. Lee, T. H. Pham, and J.-W. Ahn, "Design and operation characteristics of four-two pole high-speed SRM for torque ripple reduction," IEEE Transactions on Industrial Electronics, vol. 60, no. 9, pp. 3637-3643, 2013.

[2] S.-M. Yang and J.-Y. Chen, "Controlled dynamic braking for switched reluctance motor drives with a rectifier front end," IEEE Transactions on Industrial Electronics, vol. 60, no. 11, pp. 4913-4919, 2013.

[3] H.-Y. Yang, Y.-C. Lim, and H.-C. Kim, "Acoustic noise/vibration reduction of a single-phase SRM using skewed stator and rotor," IEEE Transactions on Industrial Electronics, vol. 60, no. 10, pp. 4292-4300, 2013.

[4] F. L. M. dos Santos, J. Anthonis, F. Naclerio, J. J. C. Gyselinck, H. Van der Auweraer, and L. C. S. Góes, "Multiphysics NVH modeling: simulation of a switched reluctance motor for an electric vehicle," IEEE Transactions on Industrial Electronics, vol. 61, no. 1, pp. 469-476, 2014.

[5] B. B. Choi and M. Siebert, "A bearingless switched reluctance motor for high specific power applications," in Proceedings of the 42nd AIAA/ASME/SAE/ASEE Joint Propulsion Conference \& Exhibit, Sacramento, Calif, USA, July 2006.

[6] M. Takemoto, K. Shimada, and A. Chiba, "A design and characteristics of switched reluctance type bearingless motors," in Proceedings of the 4th International Symposium on Magnetic Suspension Technology, pp. 49-63, 1998.

[7] F.-C. Lin and S.-M. Yang, "An approach to producing controlled radial force in a switched reluctance motor," IEEE Transactions on Industrial Electronics, vol. 54, no. 4, pp. 2137-2146, 2007.

[8] L. Chen and W. Hofmann, "Speed regulation technique of one bearingless $8 / 6$ switched reluctance motor with simpler single winding structure," IEEE Transactions on Industrial Electronics, vol. 59, no. 6, pp. 2592-2600, 2012.

[9] C. R. Morrison, M. W. Siebert, and E. J. Ho, "Electromagnetic forces in a hybrid magnetic-bearing switched-reluctance motor," IEEE Transactions on Magnetics, vol. 44, no. 12, pp. 4626-4638, 2008.

[10] Z. Xu, D. H. Lee, and J. W. Ahn, "Control characteristics of 8/10 and 12/14 bearingless switched reluctance motor," in Proceedings of the International Power Electronics Conference, pp. 994-999, Hiroshima, Japan, October 2014.

[11] W. Peng, F. Zhang, and J.-W. Ahn, "Design and control of a novel bearingless SRM with double stator," in Proceedings of the 21st IEEE International Symposium on Industrial Electronics (ISIE '12), pp. 1928-1933, IEEE, Hangzhou, China, May 2012.

[12] H. Wang, J. Liu, J. Bao, and B. Xue, "A novel bearingless switched reluctance motor with biased permanent magnet," IEEE Transactions on Industrial Electronics, vol. 61, no. 12, pp. 6947-6955, 2014.

[13] H. Wang, J. Bao, B. Xue, and J. Liu, "Control of suspending force in novel permanent-magnet-biased bearingless switched reluctance motor," IEEE Transactions on Industrial Electronics, vol. 62, no. 7, pp. 4298-4306, 2015.

[14] M. Takemoto, A. Chiba, and T. Fukao, "A new control method of bearingless switched reluctance motors using square-wave currents," in Proceedings of the IEEE Power Engineering Society Winter Meeting, vol. 1, pp. 375-380, Singapore, June 2000.

[15] M. Takemoto, A. Chiba, and T. Fukao, "A method of determining the advanced angle of square-wave currents in a bearingless switched reluctance motor," IEEE Transactions on Industry Applications, vol. 37, no. 6, pp. 1702-1709, 2001.

[16] M. Takemoto, A. Chiba, H. Akagi, and T. Fukao, "Radial force and torque of a bearingless switched reluctance motor operating in a region of magnetic saturation," IEEE Transactions on Industry Applications, vol. 40, no. 1, pp. 103-112, 2004.

[17] M. Takemoto, H. Suzuki, A. Chiba, T. Fukao, and M. A. Rahman, "Improved analysis of a bearingless switched reluctance motor," IEEE Transactions on Industry Applications, vol. 37, no. 1, pp. 26-34, 2001.

[18] X. Cao, Z. Deng, G. Yang, and X. Wang, "Independent control of average torque and radial force in bearingless switchedreluctance motors with hybrid excitations," IEEE Transactions on Power Electronics, vol. 24, no. 5, pp. 1376-1385, 2009.

[19] Y. Yang, Z. Deng, G. Yang, X. Cao, and Q. Zhang, "A control strategy for bearingless switched-reluctance motors," IEEE Transactions on Power Electronics, vol. 25, no. 11, pp. 2807-2819, 2010.

[20] L. Zhang and Y.-K. Sun, "Variable-structure control of bearingless switched reluctance motors based on differential geometry," Proceedings of the Chinese Society of Electrical Engineering, vol. 26, no. 19, pp. 121-126, 2006 (Chinese).

[21] Y. Ren and J. Fang, "High-precision and strong-robustness control for an MSCMG based on modal separation and rotation motion decoupling strategy," IEEE Transactions on Industrial Electronics, vol. 61, no. 3, pp. 1539-1551, 2014.

[22] J. Wu, Y. Sun, X. Liu, L. Zhang, G. Liu, and J. Chen, "Decoupling control of radial force in bearingless switched reluctance motors based on inverse system," in Proceedings of the 6th World Congress on Intelligent Control and Automation (WCICA '06), pp. 1100-1104, June 2006.

[23] Z. Zhu and Y. Sun, "Modified inverse decoupling control for bearingless switched reluctance motors operating in irreversible domain," in Proceedings of the 17th International Conference on Electrical Machines and Systems (ICEMS '14), pp. 1245-1250, IEEE, Hangzhou, China, October 2014.

[24] Y. Sun, Y. Zhou, and X. Ji, “Decoupling control of bearingless switched reluctance motor with neural network inverse system method," Zhongguo Dianji Gongcheng Xuebao/Proceedings of the Chinese Society of Electrical Engineering, vol. 31, no. 30, pp. 117-123, 2011.

[25] Y. Zhou, Y. Sun, and Y. Huang, "Full decoupling control of bearingless switched reluctance motor based on support vector machine inverse system," Journal of Jiangsu University (Natural Science Edition), vol. 33, no. 1, pp. 60-64, 2012 (Chinese).

[26] J. Fang and Y. Ren, "Decoupling control of magnetically suspended rotor system in control moment gyros based on an inverse system method," IEEE/ASME Transactions on Mechatronics, vol. 17, no. 6, pp. 1133-1144, 2012.

[27] J. Fang and Y. Ren, "High-precision control for a single-gimbal magnetically suspended control moment gyro based on inverse system method," IEEE Transactions on Industrial Electronics, vol. 58, no. 9, pp. 4331-4342, 2011. 
[28] X. Dai, D. He, X. Zhang, and T. Zhang, "MIMO system invertibility and decoupling control strategies based on ANN $\alpha$ th-order inversion," IEE Proceedings: Control Theory and Applications, vol. 148, no. 2, pp. 125-136, 2001.

[29] Y. Ren and J. Fang, "Current-sensing resistor design to include current derivative in PWM H-bridge unipolar switching power amplifiers for magnetic bearings," IEEE Transactions on Industrial Electronics, vol. 59, no. 12, pp. 4590-4600, 2012. 


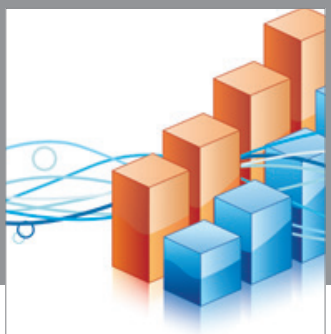

Advances in

Operations Research

vatem alat4

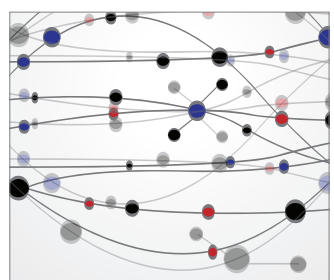

\section{The Scientific} World Journal
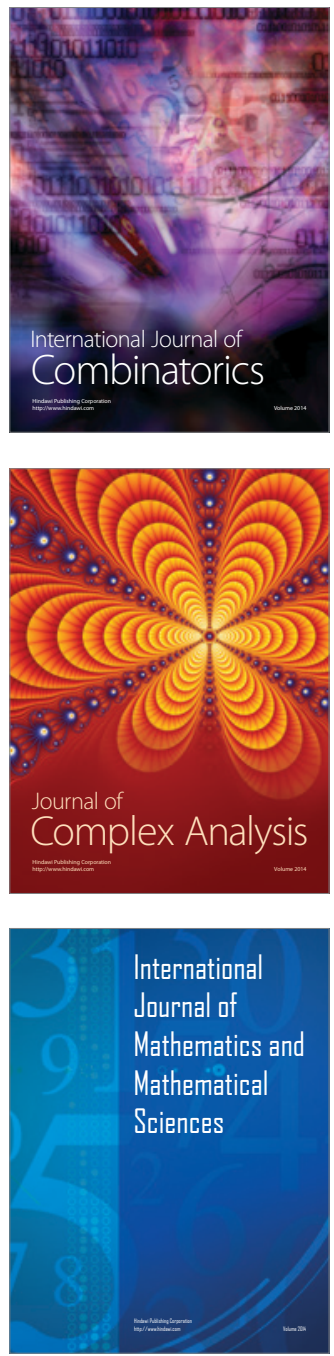
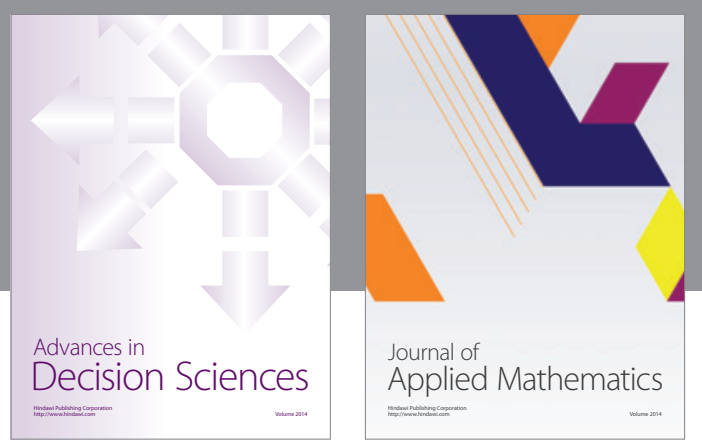

Algebra

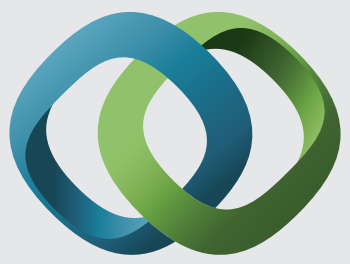

\section{Hindawi}

Submit your manuscripts at

https://www.hindawi.com
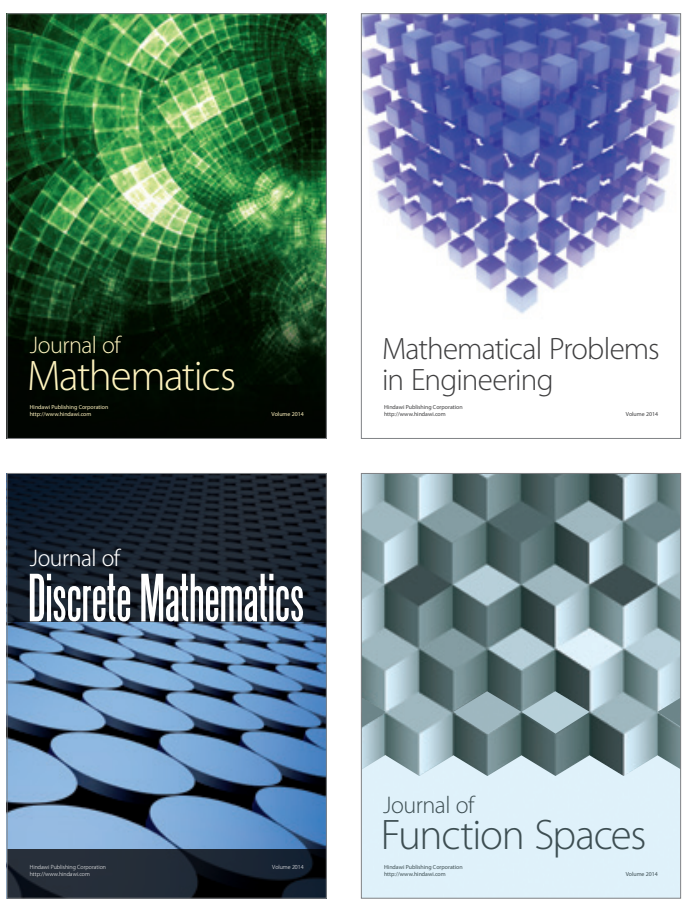

Mathematical Problems in Engineering
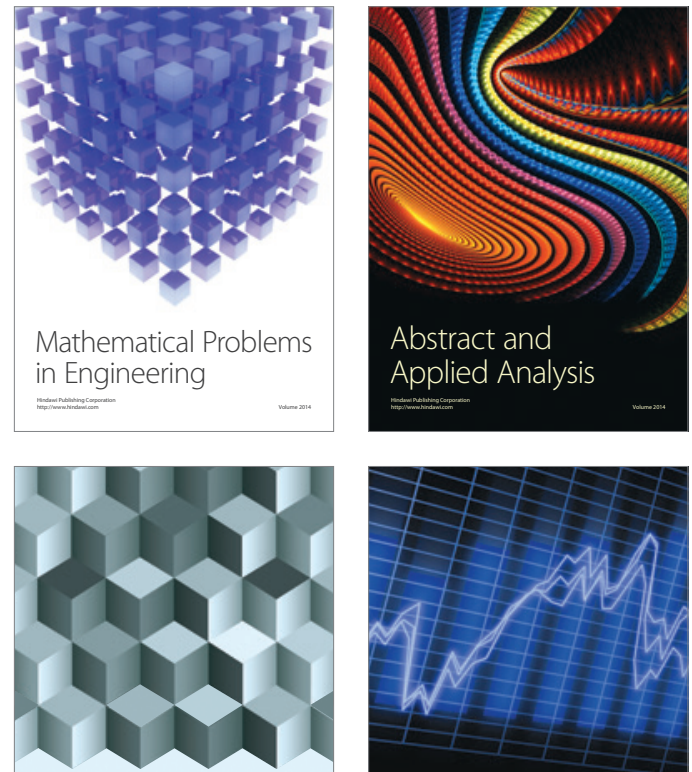

Journal of

Function Spaces

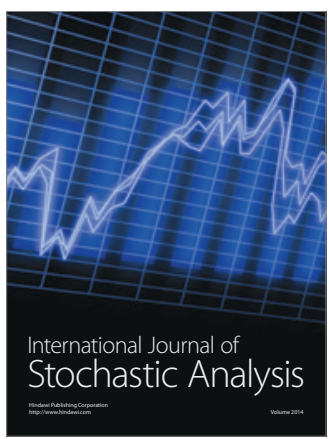

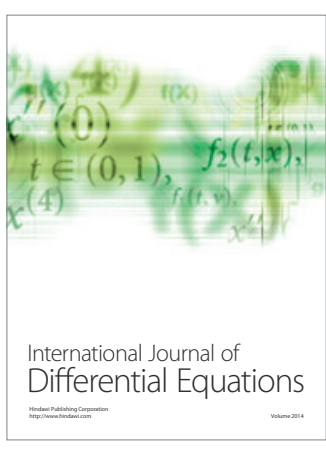
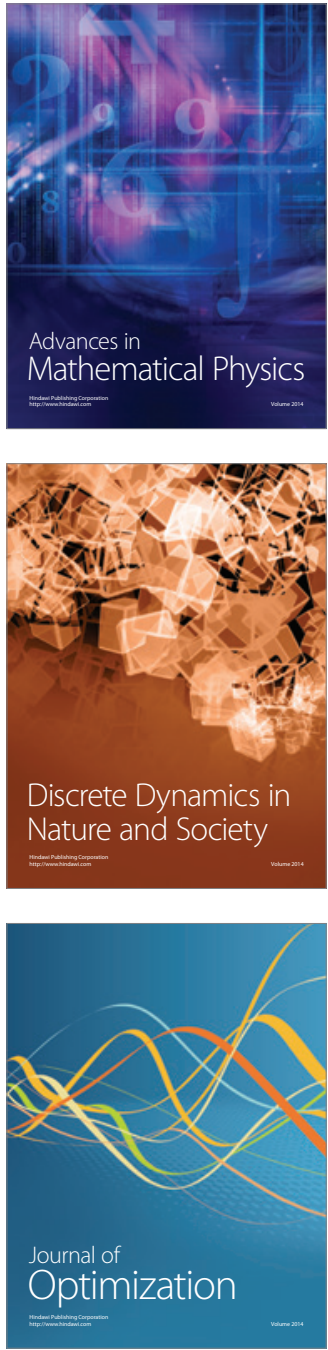